\title{
Hydrophobic Copolymers Added with Starch at the Size Press of a Paper Machine: A Review of Findings and Likely Mechanisms
}

\begin{abstract}
Ahsen E. Bildik Dal ${ }^{a}$ and Martin A. Hubbe ${ }^{b}$
This article reviews publications with the goal of understanding the role of hydrophobic copolymers added to size-press starch as a means to make paper products more resistant to penetration by aqueous fluids. The underlying technology is considered, including background related to starch, size-press equipment, and various hydrophobic copolymers and latex products that have been evaluated. The resulting hydrophobization of the paper has been reported to depend not only on the dosage of the hydrophobic additive, but also on its molecular mass and ionic form. The mechanism appears to rely on an ability of starch to serve as a temporary host for hydrophobic compounds in aqueous solution. It has been proposed that hydrophobic copolymers added with size press starch tend to migrate to the air interface during drying of the starch film, thus allowing the low-energy functional groups, such as styrene or alkyl chains, to face outwards. Further research is needed to address various mechanistic questions. There may be opportunities to further raise the performance of this type of technology as practiced within paper production factories.
\end{abstract}

Keywords: Styrene maleic anhydride; Styrene acrylate; Polyurethane; Starch; Amylose; Surface sizing; Papermaking; Hydrophobicity; Wettability

Contact information: a: Istanbul University-Cerrahpasa, Faculty of Forestry; $b$ : Department of Forest Biomaterials, North Carolina State University, Campus Box 8005, Raleigh, NC 27695-8005 USA;

*Corresponding author: hubbe@ncsu.edu

\section{Contents}

Introduction ............... 2139

Motivations for hydrophobicity. . . . 2139

Hypotheses............. 2140

Technical background ......... 2141

Overview.............. 2141

Starch products for size press ... 2141

Starch source ........... 2141

Macromolecular forms ....... 2142

Starch pasting. .......... 2142

Starch crystalline structure . . . . 2142

Starch conversion .......... 2143

Starch derivatives ......... 2144

Size press application systems . . 2144

Hydrophobic agents for size press 2145

Amounts used ........... 2145

Styrene maleic anhydride (SMA) 2145

Styrene acrylate (SA) . . . . . . 2146

Urethane copolymers (PU) . . . . 2147

Hydrophobic starch esters . . . . 2147

Other copolymers ........... . 2147

Lignin . . . . . . . . . . . . . 2148

Dispersions ........... 2149
Monomeric hydrophobic agents $\quad 2150$

Plasticizers . . . . . . . . . . . 2150

Results when using such additives 2150

Mechanistic issues . . . . . . . . . 2153

Overview .............. 2153

Delivery of mixtures to paper . . . 2153

Lucas-Washburn equation ..... 2154

Development of hydrophobicity . . . 2154

Wettability character of starch . . . 2154

Solubility parameters . . . . . . 2155

Phase separation .......... 2156

Behavior of the copolymer .... 2156

Migration of the hydrophobes . . 2158

Effects on paper's porosity ..... . 2160

Consideration of the hypotheses ... 2162

Implications, future developments. . . 2162

Laboratory research . . . . . . . 2163

Molecular dynamics simulation . . . 2164

Kinetic issues . . . . . . . . . . 2165

Developmental opportunities ... . 2165

Closing comments .......... 2166 


\section{INTRODUCTION}

Paper products that are intended for printing, packaging, and the serving of food and drinks need to be able to resist wetting or penetration by water and related fluids. As one example, optimum hydrophobicity is needed to avoid the "feathering" of printed characters in the ink-jet process. The use of just starch or its derivatives at the size press is often not enough in critical situations to achieve sufficient resistance against liquids. One way to achieve such resistance is by adding a hydrophobic copolymer together with the starch solution being used at the size press. Though the adding of hydrophobic agents during the surface-sizing of paper has been widely practiced for over 40 years (Cushing 1979; Batten 1992), many aspects of the technology are still not well understood. The starch and hydrophobic agents need to be balanced, and the formulation should completely cover the surface of the paper as a film structure. Otherwise, the hydrophobic agents may tend to hurt the formulation's ability to form a continuous film and to contribute to fluid resistance. The purpose of this review article is to consider the evidence of what factors affect the performance of hydrophobic surface sizing agents and the mechanisms by which they work.

\section{Motivations for Achieving Hydrophobicity at the Size Press}

Strength is the main goal, but there can be others

Why use the size press to make paper resist water? Highly cost-effective and timetesting procedures already exist to make paper resist aqueous fluids by treatment of the fiber suspension before paper is made (Davison 1975; Hubbe 2007). Under acidic papermaking conditions, the paper can be treated at the wet-end with low-cost and environmentally friendly additives based on rosin, which is a byproduct of the pulping of softwoods (Ehrhardt and Leckey 2020). Under neutral to alkaline pH conditions, one can employ reactive sizing agents such as alkylketene dimer (AKD) and alkenylsuccinic anhydride (ASA) (Dumas 1981). Based on the required dosages, less that a single monolayer of such reactive sizing agents is enough to render the treated paper thoroughly hydrophobic. By contrast, when hydrophobic substances are admixed with starch to be added at a size press, higher amounts are needed to achieve the same levels of resistance to aqueous fluids in comparison to hydrophobic agents added to the fiber slurry.

\section{Development of fluid resistance}

Sometimes the reason for doing something is "because it's there" (Mallory 1923). Size presses are present in thousands of paper machine systems around the world, and their main reason for existence is to impart increased surface strength, stiffness, and resistance to dusting to paper and paperboard (Lipponen et al. 2005). It takes very little additional investment to be able to add something else along with the starch to fine-tune the wettability properties of the resulting paper. It is well known that the addition of hydrophobic compounds can increase the contact angle of aqueous liquids on paper, and thereby that one can develop resistance to penetration (Cobb and Lowe 1934). A particular attraction of achieving such effects by adding hydrophobic copolymers at a size press is that no chemical reaction is required. Thus, unlike some of the sizing agents used to treat the fiber suspension before paper is made (Dumas 1981), most hydrophobic agents used by papermakers at the size press do not require any curing. Effective hydrophobicity is developed without strong dependency on the temperature of drying (Latta 1994). As will be discussed, the chemical nature of the surface-applied hydrophobic copolymer additive 
does not change in the course of drying, and therefore the resulting hydrophobicity tends to be stable over time (Hubbe 2007). Surface treatment, as a strategy to impart properties to the surface of paper, also tends to become increasingly attractive with increasing basis weight of the paper product (Exner 2002).

\section{Secondary effects}

Some of the greatest incentives to employ hydrophobic additives together with sizepress starch are related to problems caused by over-use or inappropriate use of wet-end hydrophobic treatments. For example, wet-end sizing with high levels of AKD tends to make the paper slippery (Hoyland and Neill 2001; Karademir and Hoyland 2003). The slipping tendency, when it becomes a problem, can be addressed by backing off on the AKD treatment level and replacing some of the size-press starch with a styrene-maleic anhydride (SMA) copolymer or a styrene acrylate (SA) copolymer (Batten 1992, 1995). The same strategy can be used to improve the adhesion of toner to paper (Proverb 1999; Chen et al. 2015). Certain hydrophobic copolymers, when added with starch, tend to make the paper less permeable to air, which can be desirable for some grades of paper (Batten 1995). In addition, there are reports that hydrophobic copolymers added at the size press with starch can improve the printing characteristics of paper (Gigac et al. 2014; Chen et al. 2015), or they can decrease the contamination of printing presses with dust from the paper (Batten 1995). The increasing filler content of printing papers, with the passage of years, places higher challenges with respect to achieving both hydrophobicity and surface strength of the resulting paper (Nguyen et al. 1998). Ideally the sizing should improve the print quality by controlling the absorption of printing ink while minimizing the cost of the material and achieving higher print image density (Wang et al. 2013). Often there is an economic advantage of using internal sizing and hydrophobic surface sizing additives in a synergistic manner (Barker et al. 1994; Latta 1994; Exner 2002).

While all of these effects mentioned above can be important to papermakers, the key questions to be addressed in this article are related to the development of hydrophobicity as a result of adding the copolymers and related materials with starch at a size press. As a means of focusing the discussion, the following hypotheses are proposed.

\section{Hypotheses}

Synergism between hydrophobic copolymers and starch, related to the differing character of different sides of the amylose macromolecule, makes it possible to distribute the hydrophobic substance during preparation of the mixture to be used at a size press.

A degree of self-association of the hydrophobic copolymers also plays a role in the distribution of the mixture of starch and hydrophobic copolymer.

Phase separation during the drying of a mixture of starch and hydrophobic copolymer plays a role in the development of a hydrophobicity at the paper surface.

Note that each of these three hypotheses is concerned with association. Is there suitable association between the hydrophobic additive and the starch to enable effective mixing and distribution? Is there association among the hydrophobic compounds themselves, which can affect the outcomes? And, in the end, is some kind of phase 
separation actually required as part of the mechanism by which hydrophobic properties of the paper are achieved?

Before considering evidence to support each of these three hypothesis, some background explanations are needed. The following section reviews some of what has been reported about starch, about size press equipment, about hydrophobic compounds, and some of the main effects that have been achieved by the use of such compounds at the size press.

\section{TECHNICAL BACKGROUND}

\section{Overview}

Starch is by far the most widely used additive for treatment of the surface of paper at the size press of a paper machine. This widespread usage of starch no-doubt can be attributed to its moderate cost relative to its contribution to bonding and stiffness of the paper sheet (Anderson 1997). It has been estimated that surface-applied starch constitutes about $0.5 \%$ of the mass of a typical sheet of printing paper (Anttila et al. 2012). Generally, the starch to be applied at the paper surface is prepared as a solution having a solids content in the range of 5 to $18 \%$ (Anttila et al. 2012). This starch solution, still hot from its preparation, is applied to a hot sheet of paper, which has just completed its passage through a series of steam-heated rolls. As will be discussed, advances in the design of size press equipment have allowed increasing solids levels of starch, and there have been advances in production efficiency. Batten (1992) gives the range of about $0.1 \%$ to $0.2 \%$ as typical addition levels for the hydrophobic copolymer SMA, relative to the mass of the paper product, when it is added at a size press. It is worth emphasizing that only limited information about usage rates have been reported, and one can expect a wide diversity of practices at different manufacturing sites and for different grades of paper.

In classical surface sizing with typical starch products, the subsequent penetration of liquids into to the body of the paper is inhibited to some extent by a filling in of some of the porosity of the paper. The addition of hydrophobic copolymers might delay the penetration of starch solution into paper, which could contribute to forming a more contiguous starch film on the surface. Even though the film is far from being contiguous, it can slow the progress of a wetting liquid into the porous interior of the sheet. Since hydrophobic agents are known to resist the spread of water, their addition to the hydrophilic starch mixture has potential to further slow the initial penetration of a fluid into the body of a sheet. The degree of internal sizing, as an expression of the degree of cellulose fiber resistance to wetting and water absorption, has a role in determining the amount of a sizepress formulation that is picked up. Other important factors affecting the final hydrophobization of the paper are the concentration of starch, the ratio between starch and hydrophobic additives, intrinsic features of the paper, ionic strength of additives, colloidal stability and viscosity of the size press formulation, application method, and the drying temperature (Iselau et al. 2017, 2018).

\section{Starch Products for the Size Press}

Starch source

Starch sources and product types suitable for papermaking have been reviewed elsewhere (Hoffreiter 1980; Maurer and Kearney 1998; Maurer 2009), so only summary information is needed here. Starch is a natural polymer that has alpha-D glucose units. The 
main source of commercial starches are corn (yellow dent and waxy maize), potato, and wheat. In the USA, the dominant product used for papermaking is yellow dent corn starch, which is also widely used as a food ingredient and for the manufacture of fructose. Potato starch is also widely used by US papermakers and is popular with European papermakers. Potato starch has a significantly lower gelatinization temperature and has been reported to give better water resistance compared to corn starch (Hiemstra and Vanderme 1969; Buttrick et al. 1990). In south Asia, tapioca starch is widely used.

\section{Macromolecular forms}

Two main macromolecular forms of starch exist side-by-side in typical plants. Most starch is composed of two main fractions, amylopectin and amylose. The majority of the starch present in such vegetable products as corn, potato, wheat, and tapioca, is a highly branched structure known as amylopectin. In the case of certain hybrid corn, known as waxy maize, almost $100 \%$ of the starch is of this type (Sarka and Dvoracek 2017). However, in most common plant materials, about 20 to $30 \%$ of the starch is amylose, which has a linear chain structure (Tester et al. 2004). Amylose contains mostly 1-4 alpha glycosidic linkages, and amylopectin contains 1-4 alpha-glycosidic linkages along with 16 alpha-glycosidic linkages at the branch points. The ratio of amylose to amylopectin and polymerization degree as well as average particle size, density, starch granule shapes vary according to source of starches.

Starch granules are insoluble in cold water because of organized, hydrogen-bonded structures. When a water suspension of starch is heated, it does not change a lot until reaching a critical temperature that is known as the pasting or gelatinization temperature. At the paper mill, usually the first step in preparing starch for addition to paper involves the heating of a well-mixed aqueous dispersion of starch grains. This can be done either at atmospheric pressure (batch cooking) or in a continuous, pressurized system (jet cooking) (Rankin et al. 1976).

\section{Starch pasting}

Whichever type of cooking system that is selected, the starch granules need to undergo a process known as pasting or gelatinization (Ratnayake and Jackson 2009). During this process the grains swell, loose their solidity, and eventually release their contents into the bulk phase (Ai and Jane 2015). The granules lose their distinctive optical characteristics as they begin to swell. During these transitions, the viscosity of the mixture can rise, first partly due to the swelling of the grains, and later due to the polymeric starch, which may be present either as dissolved macromolecules or as gelatinous material. The pasting temperature range and the paste properties of starch depend on the starch type and its complex colloidal nature. Typical values for the pasting temperature of different starch types are 60 to $64{ }^{\circ} \mathrm{C}$ (potato), 64 to $75{ }^{\circ} \mathrm{C}$ (dent corn and waxy maize), 64 to $74{ }^{\circ} \mathrm{C}$ (tapioca), and 57 to $66^{\circ} \mathrm{C}$ (wheat) (Ai and Jane 2015).

\section{Starch crystalline structure}

The tendency of starch to contain and to form various types of crystals can have a major influence on its behavior. Papermakers are often acutely aware of the tendency of the amylose portion of starch to undergo retrogradation (Miles et al. 1985; Fredriksson et al. 1998; Fechner et al. 2005; Liu et al. 2007; Wang et al. 2015b). Retrogradation of starch to be used in surface sizing manifests itself as precipitation from solution and a decrease in the bond-forming ability of the starch. In particular, solutions of freshly cooked mixtures 
of starch that contain amylose are especially susceptible to retrogradation if they are held for many minutes within a temperature range of about 67 to $89{ }^{\circ} \mathrm{C}$ (Andersson et al. 2008). It is well known that amylopectin, due to its highly branched nature, is resistant to retrogradation (Hsieh et al. 2019). In other words, even though amylopectin can exhibit a high degree of crystallinity while in the grain (Schirmer et al. 2013), it does not tend to precipitate once it has been put into solution.

Among several types of crystals that can be formed by the amylose component of starch, one of the most important, from the standpoint of hydrophobic treatment of paper, is the V-type. This is composed of a single helix of starch, the central axis of which is often occupied by a natural lipid molecule, i.e. a hydrophobic compound (Mikus et al. 1946; Immel and Lichtenthaler 2000; Conde-Petit et al. 2006; Putseys et al. 2010; Obiro et al. 2012; Meng et al. 2014). Figure 1, which is redrawn based on results reported by Immel and Lichtenthaler (2000), represents one "wrap" of the helix of amylose when in a $\mathrm{V}_{\mathrm{H}}$-type helical conformation. Note that a predominance of non-polar $-\mathrm{CH}$ groups and a lack of polar $-\mathrm{OH}$ groups facing inward can account for the hydrophobic character within the core of the helix.

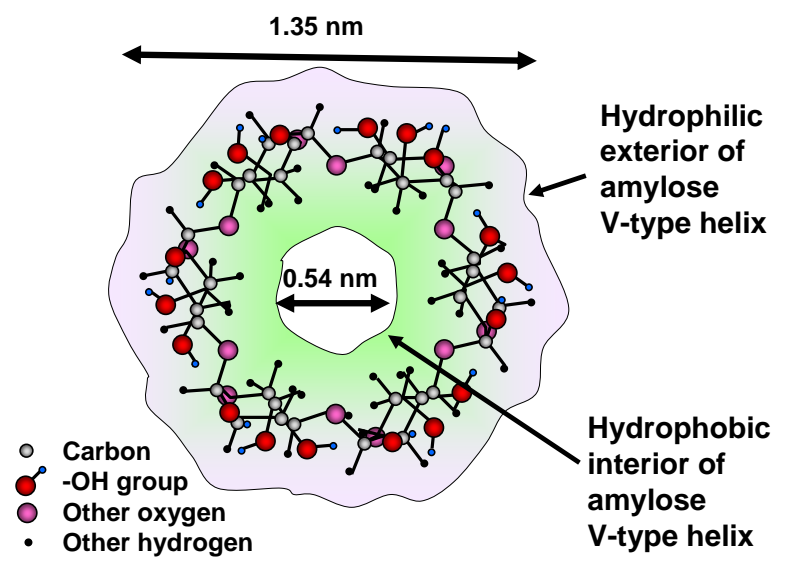

Fig. 1. End view of amylose $\mathrm{V}_{\mathrm{H}}$-type helix. Figure drawn based on positions of atoms presented by Immel and Lichtenthaler (2000)

When starch is cooked, then cooled, it has been reported that some of the amylose may form itself into A-type complexes; these consist of tightly wound double helices having a hydrophilic character (Conde-Petit et al. 2006). Such complexes have no ability to accommodate lipophilic molecules. Since the A-type complexes are persistent in solution, the development of A-type complexes generally renders the starch less compatible with hydrophobic materials. Self-association among A-type complexes has been reported (Conde-Petit et al. 2006), which is consistent with the known tendency of amylose to precipitate from solution (Liu et al. 2007).

\section{Starch conversion}

Due to the high shear rates associated with high-speed application of starch solutions to the paper surface, during production of the paper, essentially all starch that is to be used at the size press already has been decreased in molecular mass. The term "conversion" is widely used to denote such processes. In years past this was most often accomplished by treatment with amylase, i.e. "enzyme conversion" (Hughes and Craig 
1950; Cave and Adams 1968). Reduction in the degree of polymerization (DP) of starch also can be achieved by oxidation, using ammonium persulfate, perborates, or hydrogen peroxide (Hiemstra 1972; Brogly 1978). Though such treatments to reduce the molecular mass can make it possible to apply solutions of starch using high-speed processes, there also can be a penalty if the mass decrease is excessive. For example, vanSoest et al. (1996) showed that thermoplastic starch specimens prepared with higher molecular mass had higher strain and tearing energy compared to starch with a low DP.

\section{Starch derivatives at the size press}

Starch can be chemically modified in various ways to adjust its properties, including its solubility in water and the characteristics of its resulting films. Chemical conversion of starch tends to reduce the molecular mass, which lowers the solution viscosity. Another benefit is that chemically derivatized starch is less prone to retrogradation, which entails the precipitation of insoluble crystals (BeMiller 2009). Starch can be used for many reasons, e.g. as a hydrophobic agent in surface size, as a binder for coatings, or as a bonding agent in the papermaking process (Maurer 2009). For the development of the barrier properties, film formation must be excellent, which increases the need for plasticizers, such as glycerol (Lourdin et al. 1997; Jansson and Järnström 2005), PVOH (poly-vinyl alcohol), or ethylene-modified PVOH. However, modified starches with a quaternary dodecylammonium chloride is an alternative to traditional plasticizers, especially for use in food packaging films to provide oxygen barrier and oil resistance of food contact paper packaging. The film-forming properties of the hydrophobically modified starch improves barrier properties of paper and paperboard (Andersson et al. 2008). A widely used option is to prepare oxidized starch (Lee et al. 2002; Mešić et al. 2004; Cui and Jing 2012; Iselau et al. 2018). Starch oxidation can be viewed as a side effect of certain starch conversion treatments, as described in the previous paragraph. The main concern is the colloidal stability of the formulation in the presence of electrolytes. The addition of salt has been found to adversely affect the hydrophobic sizing performance of positively charged hydrophobic emulsions added to size-press starch, whereas the addition of salt promoted the sizing effect of negatively charged hydrophobic emulsions added to starch (Iselau et al. 2018). In particular, $\mathrm{Na}_{2} \mathrm{SO}_{4}$ was found to be more detrimental than $\mathrm{NaCl}$ and $\mathrm{CaCl}_{2}$ (Iselau et al. 2017). The situation is explained by the valence of the anion, and it was inferred that hydrophobization can be controlled by the aggregation of polymer particles. Oxidized starch has the advantage of being highly soluble in water, but its hydrophilic character can make it more challenging to achieve water resistance in the resulting paper. Hydroxyethylated starch is a popular choice for size-press application due to its high resistance to retrogradation and its superior film-forming properties (Oja et al. 1991; Wulff et al. 1998; Shirazi et al. 2008). Cationic starches, which are very popular for wet-end addition to the fiber suspension, are also being used to an increasing extent at the size press (Anttila et al. 2012). Some positive features reported for cationic size-press starch include better holdout at the paper surface (Lee et al. 2002; Shirazi et al. 2008) and better retention in the paper if and when the material is recirculated back to the papermaking process (Hamerstrand et al. 1979; Roberts et al. 1987).

\section{Size-press Application Systems}

Advances in the available equipment for surface application also have contributed to the implementation of effective hydrophobic treatments. The traditional and still widely used way to apply a starch solution to the paper's surface is called a pond-type size press 
(Klass 1990). In this format, the starch solution is poured into the in-going nip between a size-press roll and the paper web. Any excess starch that does not enter the nip between the paper and the roll eventually flows to the front or back side of the size press, where it is collected and returned to the distribution system. An inherent problem with the pondtype size press is that the hot solution of starch contacts the sheet for a relatively long time, e.g. about 1 to 5 milliseconds. This amount of exposure increases the penetration of the solution into the sheet. Not only does the partial wetting of the paper make web-breaks more likely, but the potential benefits in terms of surface strength and paper stiffness are diminished by too much penetration.

The time of contact between the starch solution and the paper, before the paper enters the size press nip, is greatly reduced when running various designs of size-press that generally fall under the category of "film press". In one such system, the blade-metering size press, a blade is used to meter a film of starch solution onto a rubber-covered roll, and the paper does not encounter the fluid until it enters the nip (Rennes 1998). Such systems not only decrease the frequency of web breaks at the size press, but they also permit higher concentrations of starch solution to be used. Benefits include better hold-up of the starch near to the surface of the paper, which provides higher stiffness and surface strength. As in the case of I-beam construction, a material can be made stiffer if there is a way to increase the Young's modulus of the outer layers (Lee et al. 2002; Lipponen et al. 2004). Another option is to apply infrared drying to immobilize the starch rapidly just after it has been applied (Rennes 1998). These issues have great relevance for surface-applied hydrophobic agents, since they may influence the location and the film-like nature of the starch after its application at a size press.

\section{Hydrophobic Agents for the Size Press \\ Amounts used}

Hydrophobic agents, when they are added at the size press, usually can be envisioned as substituting for some of the starch solids. The most widely used treatments are copolymers, within which the hydrophobicity is contributed by either styrene or appended alkyl chains. To achieve sufficient solubility to be applied by means of an aqueous distribution system, the copolymers also typically include maleic or acrylic acid monomeric units. The level of addition is often in the range of $1 \%$ to $10 \%$ of the starch amount, based on dry mass (Batten 1992).

\section{Styrene maleic anhydride and its ester form}

The best-known hydrophobic compounds for surface application to paper are of the styrene maleic anhydride (SMA) type (Cushing 1979; Batten 1992, 1995; Latta 1994; Wang et al. 1997; Gigac et al. 2014). The general chemical structure is illustrated in Fig. 2. As shown, a key option provided to users is the type of counter-ion employed in the formulation. Solubility in water is achieved by usage of highly soluble monomeric ions, especially sodium or ammonium.

As shown by part B of Fig. 2, the balance between hydrophilic and hydrophobic character can be adjusted by partial esterification of some of the carboxylic acid groups of SMA with an alkyl chain (Shibihara and Tominaga 1975; Gigac et al. 2014). Such esterification increases the hydrophobic character of the copolymer. In addition, SMA products are available in different molecular mass ranges. According to Batten (1992), a minimum mass of about 30,000 Daltons is needed in order to achieve effective 
hydrophobization. A follow-up article (Batten 1995) specified a molecular mass of at least 50,000 to achieve the best results.

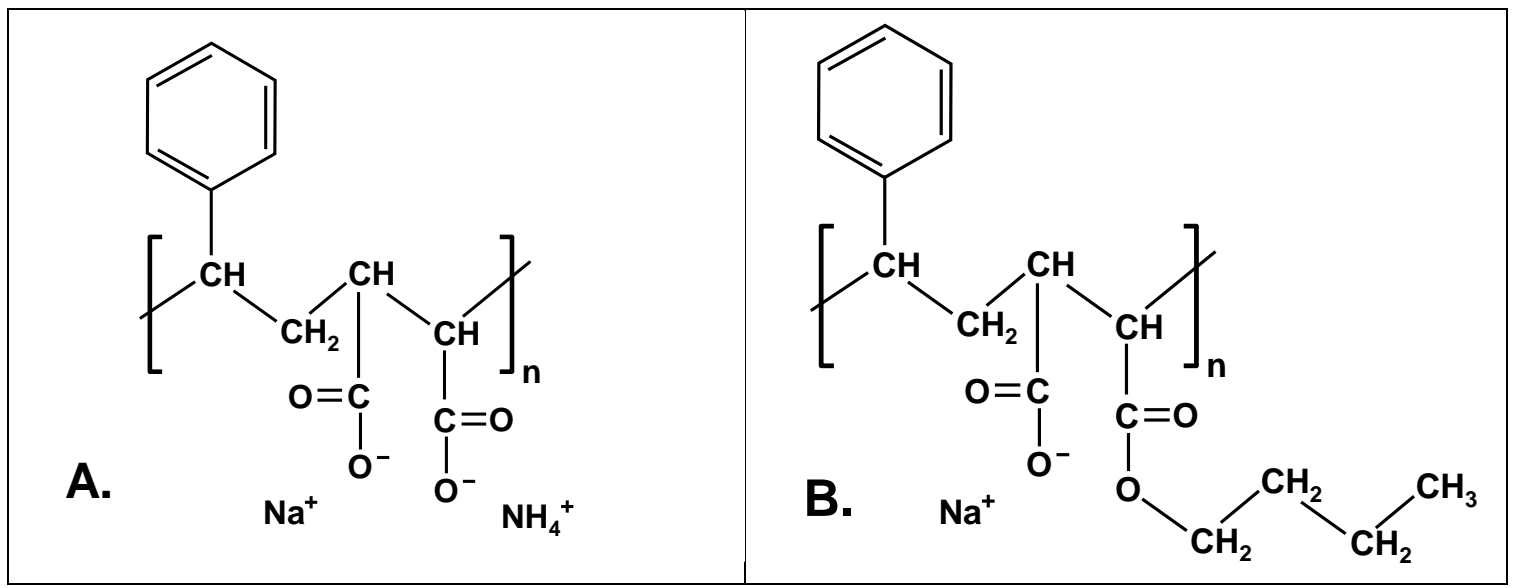

Fig. 2. Basic structure of styrene maleic anhydride (SMA) copolymers for use at the size press: $A$. Ordinary SMA; B. Esterified SMA

Styrene acrylate

Another widely sold class of hydrophobic copolymers intended for utilization at the size press is styrene acrylate (SA) (Batten 1992; dePierne et al. 1992; Barker et al. 1994; Sodeyama et al. 2014; Chen et al. 2015). The rudimentary structure of the SA class of hydrophobic polymers for surface sizing is shown in Fig. 3.

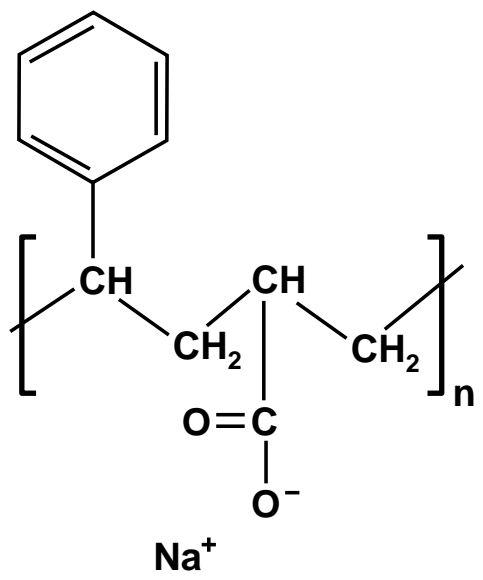

Fig. 3. Basic structure of styrene acrylate copolymers for use at the size press

The main difference, compared to the SMA products, is that there is only a single carboxylic acid in each of the hydrophilic groups, rather than a pair. In principle, a range of products having different levels of hydrophobicity can be prepared by adjusting the ratio of the two co-monomers. In addition, as in the case of SMA, the SA products can be rendered more hydrophobic by partial alkyl-esterification of carboxyl groups on the chain (Carceller and Juppo 2004; Radovanović et al. 2007; Cui and Jing 2012; Stankovska et al. 2014; Özdemir et al. 2017a,b). Barker et al. (1994) demonstrated the effectiveness of SA products to increase the water resistance of alkaline paper sheets, wherein oxidized starch 
was the principle size-press additive. According to Proverb (1999), whereas SMA products work best in combination with base paper that contains aluminum sulfate, the SA products have been optimized to work well in paper prepared under alkaline papermaking conditions.

\section{Urethane copolymers}

A third class of widely-used hydrophobic copolymers for the size press is based on polyurethane (PU) chemistry (Pask 1982; Batten 1992). Figure 4 shows the basic chemical composition reported for this type of product. According to Batten (1992), the PU products have been found to outperform the SMA and SA products with respect to achieving increases in hydrophobicity. More recently there have been developments in which PU chemistry is being combined with various other monomers (Guo et al. 2012, 2013, 2014; Zhu et al. 2016; Fei et al. 2017). A cationic water-based polyurethane dispersion has been shown to significantly improve the paper's resistance to water as well as surface properties and printability compared to base papers (Xu and $\mathrm{Hu} 2009$ ). Notably, a cationic PU product can be prepared without the usage of organic solvent (Shen et al. 2010).

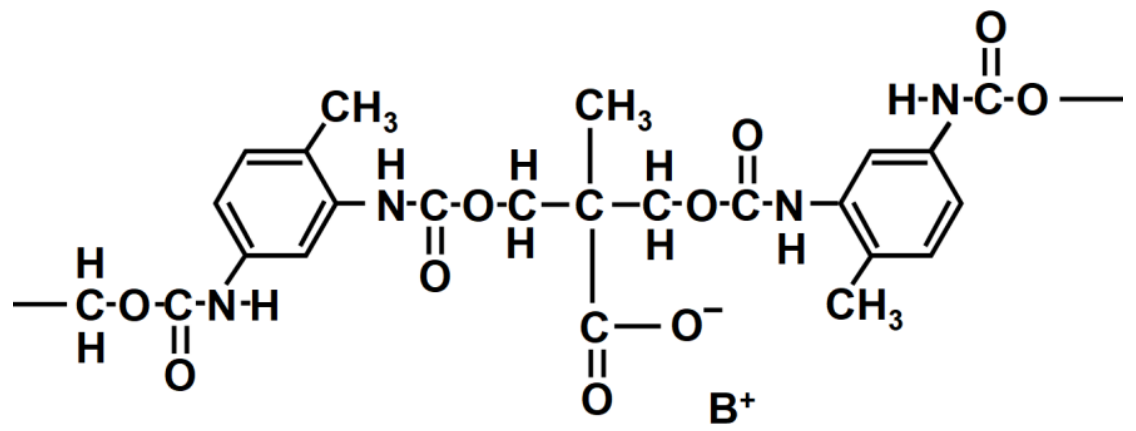

Fig. 4. Part of the linear chain structure of urethane copolymers for use at the size press. Structure redrawn based on Batten (1992)

\section{Hydrophobic starch esters}

In view of the fact that starch is the major component in most size-press operations, it makes logical sense to consider the use of hydrophobically modified types of starch. Due to the abundance of $-\mathrm{OH}$ groups, esterification or etherification can be used to increase starch's hydrophobic character. Several such products have shown effectiveness as sizepress additives to increase the water resistance properties of paper (Aloi et al. 2001; Mešić et al. 2004; Thirathumthavorn and Charoenrein 2006; Andersson et al. 2008; Jonhed et al. 2008; Zhou et al. 2009; Horchani et al. 2010; Anttila et al. 2012). Of these reports, one of the most striking observations was the much greater hydrophobic effect of long-chain alkyl chains (octenylsuccinate) compared to shorter chains (Anttila et al. 2012). Also, adding glycerol to the warm hydrophobically modified (HM) potato starch solution decreased the glass transition temperature, the storage modulus, and the water vapor permeability (WVP) of the HM starch films (Jonhed et al. 2008).

\section{Other copolymers}

Because the hydrophobic copolymers used in surface sizing generally are not reactive, it makes logical sense that a wide range of chemistries have the potential to be effective - possibly as a result of optimization of hydrophilic and hydrophobic components. 
Table 1 lists combinations that have been reported in articles and patents. In addition to revealing a high level of diversity, another trend that starts to emerge more clearly in Table 1 is the fact that many of the copolymers have a positive charge (cationic). A positive charge provides a mechanism by which the copolymer can be effectively associated with such anionic substances as oxidized starch. Dimethyl tallow epoxypropyl ammonium halogens and quaternary ditallow methyl epoxypropyl ammonium halogens can be used as hydrophobic surface sizing chemicals; these additives were shown to form a hydrophobic layer on the paper surface and to result in increased toner adhesion value (Koskela et al. 2006).

Table 1. Other Copolymers Reported to Render Paper Hydrophobic When Added to Surface-applied Starch

\begin{tabular}{|l|l|}
\hline Copolymer combination & Citation \\
\hline Cationic copolymer based on acrylic monomers & Hans et al. 1965 \\
\hline Copolymer of acrylic ester and acrylic acid, etc. & Tominaga \& S. 1978 \\
\hline Maleic anhydride with dicyclopentadiene, half-amides of ammonia & Peterlein et al. 1980 \\
\hline Copolymers with maleic acid, diisobutylene, vinyl, urea & Sackmann et al. 1984 \\
\hline Alpha-olefins / maleic anhydride / polyamine (cationic) & Schurmann et al. 1989 \\
\hline Cationic acrylate / methacrylic acid ester of C10 to C22 alcohol & Bung et al. 1992 \\
\hline Hydrophobically modified polyacrylamide & Takaki et al. 1997 \\
\hline Cationic dispersion copolymer / C8 to C30 olefins & Dahmen et al. 1999 \\
\hline Polymer latex (styrene, acrylate, and unsaturated carboxylic acid) & Varnell 2000 \\
\hline Maleic anhydride / styrene / vinyl alkyl ether / fatty amine & Inaoka et al. 2009 \\
\hline Tertiary amino compound, alkyl methacrylate, and styrene & Inaoka et al. 2011 \\
\hline Collagen with methyl acrylate and vinyl acetate & Wang et al. 2013 \\
\hline Hemicellulose / acrylamide / methacryloyloxy ethyl trimethyl (cat.) & Dong et al. 2014 \\
\hline Cationic starch, methacrylic acid ester, and styrene & Sodeyama et al. 2016 \\
\hline Styrene / butyl acrylate & Özdemir et al. 2017a \\
\hline Cationic styrene / ethylhexyl acrylate & Özdemir et al. 2017b \\
\hline Poly(vinyl alcohol) / (itaconic acid) / (acrylamide) amphoteric & Ni and Jing 2019 \\
\hline Collagen reacted with diglycidyl ether, butyl acrylate, and styrene & Wang et al. 2018, 2019 \\
\hline
\end{tabular}

\section{Lignin}

Though the lignin removed from wood during pulping is most often used as a fuel source by the pulp and paper industry (Chakar and Ragauskas 2004; Gellerstedt 2015), its properties have a lot in common with many of the copolymers described above. Like SMA, $\mathrm{SA}$, and PU, lignin contains aromatic rings. Among the three main components of wood (which also contains cellulose and hemicellulose), lignin has the greatest hydrophobic character. But like the other copolymers considered, it also contains various hydrophilic groups, depending on the source of the lignin and the details of processing. Dong et al. (2015) reported the successful hydrophobic sizing of paper by treating the effluent of alkaline peroxide mechanical pulping (APMP) with aluminum sulfate (alum), where the combination is mixed with size-press starch. The hydrophobizing effect was attributed to the lignin, fatty acids, and other extractives of wood. The effects of alum in promoting hydrophobization of paper have been well known for many years (Strazdins 1989), but sizing with alum and rosin products (obtained from wood extractives) has mainly been practiced at the wet end of the paper machine. Han and Cho (2016) showed related results by adding black liquor (from kraft pulping) together with alum to size-press starch. More recently, Kopacic et al. (2018) studied a series of technical lignins and showed that kraft lignin held considerable promise as a hydrophobic agent for surface sizing. Besides, the 
results showed that the lignin-sized specimens had improved strength properties, which were at least $10 \%$ higher compared to unsized paperboard, in addition to improvements related to air permeability, hydrophobicity, and water absorptiveness (Kopacic et al. 2018). Recently it has been shown that crude wood rosin and derivatives have potential as hydrophobic surface additives with cationic starch in size press application (Bildik Dal et al. 2020).

\section{Dispersions}

Certain of the articles and patents describing hydrophobic copolymers intended for use at the size press have described the particulate-like nature of the materials. These publications and patents are listed in Table 2. For instance, Carceller and Juppo (2004) observed $30 \mathrm{~nm}$ particles based on field-emission scanning electron microscopy under freezing conditions, when studying a styrene-acrylate ester derivative mixed with a starch solution. In addition to electron microscopy, some other researchers have based their size analysis on rates of Brownian diffusion, using light scattering methods to evaluate hydrophobic substances that have been added with size press starch (Yang and Deng 2000; Guo et al. 2012, 2014; Xu and $\mathrm{Hu}$ 2012; Wang et al. 2013; Wang et al. 2015a; Fei et al. 2017). The development of such methods may give the impression that the addition of hydrophobic nanoparticles or microscopic particles at the size press may be something new. It is worth bearing in mind, however, that the addition of emulsified wax at the size press has been known for many years (Davison 1975). By contrast, it appears that an emerging focus is on products that can be best described as latex, including cationic latex dispersions.

Table 2. Particulate Nature of Certain Copolymers Reported to Render Paper Hydrophobic When Added to Surface-applied Starch

\begin{tabular}{|c|c|c|}
\hline Copolymer combination & $\begin{array}{l}\text { Particle size } \\
(\mathrm{nm})\end{array}$ & Citation \\
\hline Cationic copolymers (styrene / vinyl cationic) & $<100$ & Ono \& Deng 1997 \\
\hline Cationic copolymers (styrene / vinyl cationic) & 30 to 41 & Yang and Deng 2000 \\
\hline Styrene acrylate ester & 30 & Carceller \& Juppo 2004 \\
\hline Polyurethane copolymer (styrene acrylate, DMPA) & 25 to 190 & Guo et al. 2012 \\
\hline Cationic latex (styrene and acrylates) & 70 to 700 & Xu \& Hu 2012 \\
\hline Polyurethane copolymer & 90 to 180 & Guo et al. 2013 \\
\hline Cationic latexes with styrene and acrylates & 42 to 118 & Yan et al. 2013 \\
\hline Polyurethane copolymer (IPDI/PCL/DMPA/EDA) & 35 to 85 & Guo et al. 2014 \\
\hline Styrene acrylate & 88 to 129 & Chen et al. 2015 \\
\hline Styrene / butylacrylate with various stabilizers & 30 to 65 & Iselau et al. 2015 \\
\hline Cationic silicone-acrylic latex & 74 to 128 & Wang \& Fang 2015 \\
\hline Polyurethane with acrylate & 20 to 300 & Wang et al. $2015 \mathrm{a}$ \\
\hline Polyurethane (PCL/DMPA/PTMG/IPDA) & 25 to 65 & Zhu et al. 2016 \\
\hline Polyurethane / polyacrylate & 51 to 75 & Fei et al. 2017 \\
\hline Styrene / butylacrylate with cationic stabilizer & 30 to $70+$ & Iselau et al. 2017 \\
\hline Styrene / butylacrylate & 61 to 90 & Özdemir et al. 2017a \\
\hline Collagen crosslinked with GDE or TDE & 90 to 130 & Wang et al. 2018 \\
\hline
\end{tabular}

Notes: DMPA = dimethylol-propionic acid; IPDI = isophorone diisocyanate; $\mathrm{PCL}=$ polycaprolactone diol; EDA = ethylenediamine; PTMG = polytetramethylene glycol; IPDA = isophorone diamine 


\section{Monomeric hydrophobic agents}

The hydrophobic agents so far discussed all can be classed as copolymers or polymers. Given the fact that monomeric hydrophobic compounds are widely used as wetend additives (Prinz and Schultz 2006; Hubbe 2007), it is reasonable that they ought to be considered as serious candidates for size-press addition as well. In fact, evidence suggests that alkylketene dimer (AKD) that is added at the wet end often retains its chemical reactivity until after the size press; at that point it is able to react with the size press starch, thus contributing to the fluid-resistance of the paper (Brungardt 1997).

The reactive monomeric sizing agents, i.e. AKD and alkenylsuccinic anhydride (ASA), are not often used at the size press, each for a different reason. The problem with AKD is that surface application renders the paper too slippery for most applications (Hoyland and Neill 2001). Additional challenges related to AKD sizing include long curing times and development of a ketone byproduct that does not contribute efficiently to hydrophobization. The main problem with ASA is that that relatively high temperatures associated with size-press starch solutions would cause rapid hydrolytic breakdown, yielding a tacky mixture (Wasser 1987). In all cases, a loss of hydrophobicity of paper is expected after application of typical hydrophilic starch products at the size press (Batten 1992; Brungardt 1997). It is also worth noting that SMA and SA products, which tend to increase the coefficient of friction of paper, can act as a counter-influence against the slipperiness imparted by AKD when it is used at excessive levels. In addition, whereas AKD sizing often exhibits reversion with time, the copolymer additives at the size press are not subject to such issues.

Rosin sizing has been successfully demonstrated at the size press (Ullmann 1987). As in the case of wet-end rosin sizing, the rosin was combined with aluminum sulfate, which served as an anchor for the rosin after drying of the paper. As already noted, Dong et al. (2014) showed that increased hydrophobicity could be achieved by size press addition of wood extractives isolated from alkaline peroxide mechanical pulping effluent; it was postulated that the effects were largely due to fatty acids and their interactions with alum. Results are consistent with similar effects that have been achieved with alum and fatty acids added to the papermaking furnish (Gaiduchenya 1973). A common feature of all of these systems is that they involve the use of alum, an additive that otherwise is not often considered for size press applications.

\section{Plasticizers}

In addition to hydrophobic copolymers, many size press formulations have been prepared with additives that might be called plasticizers. The term implies that the additive renders the resulting film more stretchable. Such substances have the potential not only to affect the quality of a starch-based film, but they also may affect its hydrophobic nature after drying. Glycerol, poly(vinyl alcohol) (PVOH), and rosin all of been shown to be effective as plasticizers (Jonhed et al. 2008; Domene-López et al. 2018). Andersson et al. (2008) showed that a when PVOH and glycerol were separately added to solutions of hydrophobically modified starch, the glycerol rendered the resulting films hydrophilic. By contrast, the PVOH achieved a plasticizing effect without changing the hydrophobic nature of the film.

\section{Results When Using Hydrophobic Additives at the Size Press}

Before considering the mechanisms by which hydrophobic size press additives function, one important topic to cover is the effects of those additives on paper properties. 
The effects, as well as factors governing those effects, can be used later as evidence when seeking to explain what is happening at a nanometer scale during the surface treatment and during the drying of the surface-sized paper.

\section{Water holdout and hydrophobicity}

There probably would be little interest in hydrophobic size-press additives if they had no effect on the wettability or water absorptivity of the treated paper. Accordingly, Table 3 summarizes key findings related to either wettability (i.e. contact angles of water) or penetration rates. As shown, hydrophobizing effects were demonstrated for many different additives to size-press formulations, using three different kinds of assessment.

Table 3. Evidence of Hydrophobic Effects of Additives Used with Size-press Starch

\begin{tabular}{|c|c|c|}
\hline System & Hydrophobic Effect & Citation \\
\hline $\begin{array}{l}\text { SMA, different styrene ratios, molecular } \\
\text { mass }\end{array}$ & Higher HST seconds & Batten 1992 \\
\hline SMA, sodium form & Higher HST seconds & Latta 1994 \\
\hline Cationic microparticle based on styrene & Higher contact angles, & Ono \& Deng 1997 \\
\hline SMA & $\begin{array}{l}\text { Higher HST seconds, } \\
\text { Lower Cobb values }\end{array}$ & Wang et al. 1997 \\
\hline SMA esters & $\begin{array}{l}\text { Higher contact angles, } \\
\text { Higher HST seconds }\end{array}$ & Garrett \& Lee 1998 \\
\hline Styrene acrylate copolymers & Higher Contact angles & Proverb \& B. 1999 \\
\hline Cationic polystyrene particles & Higher HST seconds & Yang \& Deng 2000 \\
\hline Cationic \& anionic styrene acrylates & Lower Cobb values & Bung 2004 \\
\hline Hydrophobic potato starch & Lower Cobb values & Mešić et al. 2004 \\
\hline Hydrophobic potato starch with glycerol & Lower Cobb values & Jonhed et al. 2008 \\
\hline Polyurethane latexes & Lower Cobb values & Guo et al. 2012 \\
\hline Styrene acrylate & Lower Cobb values & Xu \& Hu 2012 \\
\hline Polyurethane latexes & Lower Cobb values & Guo et al. 2013 \\
\hline Collagen, methyl acetate \& vinyl acetate & Higher Contact angle & Wang et al. 2013 \\
\hline Polyurethane latexes & Lower Cobb values & Guo et al. 2014 \\
\hline Cationic silicone acrylic latex & $\begin{array}{l}\text { Higher Contact angles } \\
\text { Lower Cobb values }\end{array}$ & Wang \& Fang 2015 \\
\hline Polyurethane latexes & Lower Cobb values & Wang et al. 2015a \\
\hline Polyurethane latexes & Lower Cobb values & Zhu et al. 2016 \\
\hline Polyurethane latexes & Higher Contact angles & Fei et al. 2017 \\
\hline Styrene / butylacrylate copolymers & Lower Cobb values & Iselau et al. 2017 \\
\hline Styrene / butylacrylate copolymers & Lower Cobb values & Özdemir et al. 2017b \\
\hline Styrene / butylacrylate copolymers & Lower Cobb values & Iselau et al. 2018 \\
\hline Technical lignin & Lower Cobb values & Kopacic et al. 2008 \\
\hline Collagen with butylacrylate and styrene & Higher Contract angles & Wang et al. 2018 \\
\hline Collagen with butylacrylate and styrene & Lower Cobb values & Wang et al. 2019 \\
\hline
\end{tabular}

Notes: SMA means styrene maleic anhydride; HST means Hercules Size Test (TAPPI Method T 530 ), which is based on the time required for a green-colored solution of formic acid to penetrate a sheet of paper enough to change its reflectivity on the opposite side by a specified amount. The Cobb test (TAPPI Method T441) is based on weight gain. The listed contact angle tests were carried out with pure water.

Porosity effects

It makes intuitive sense to expect that an aqueous fluid will penetrate more quickly into a material that has an open, porous structure. If a hydrophobic copolymer renders a 
starch solution more effective in closing up the entrances to paper's porous structure, then one would expect that system to be more effective. Batten (1992) reported that both SMA and SA products contribute to greater film integrity of the starch film. This is manifested in increased values of Gurley Densometer, which is a commonly used measure of dry paper's resistance to air flow. The sodium form of SMA was reported to be particularly effective for increasing the Gurley Densometer values (Batten 1995).

\section{Strength contributions}

Contributions to the strength of starch films have been reported for certain hydrophobic additives to the size press. It is worth noting that many of the surface-applied hydrophobic substances can be classed as latex products, and latex products are used as bonding agents in paints and other applications. Guo et al. (2012) and Wang et al. (2015a) reported higher strength attributes, including burst strength, when polyurethane-based latex was added with size-press starch to paper. Wang et al. (2013) reported similar strength gains when adding a collagen-based latex with starch to paper's surface, and Yan et al. (2013) reported similar strength gains when adding a cationic latex based on styrene and acrylates with starch to paper's surface.

\section{Effects of base-sheet properties on surface-size hydrophobic treatments}

Certain studies have shown evidence that the effectiveness of surface-applied hydrophobic additives depends on base-sheet properties, especially the porous nature of the base paper and the extent to which it had been hydrophobically treated at the time of its formation. The base-sheet porosity can be reduced in principle by input of sufficient mechanical energy during the refining of kraft fibers (Gharehkhani et al. 2015). Base-sheet porosity also depends on the ratio of hardwood to softwood fibers, with the hardwood generally yielding smaller pores (Forsström et al. 2003). Related results in the absence of hydrophobic size-press additives have been reviewed by Aloi et al. (2001). In general, a more closed sheet (less porous) can be expected to hold out a starch film nearer to the paper's surface, thus giving greater contributions to paper's stiffness and reduction of air permeability. The same factors have been shown to promote greater effectiveness of surface-applied hydrophobic agents (Aloi et al. 2001). Batten (1992) reported that there appeared to be a threshold of both Gurley Densometer values and internal sizing (basesheet hydrophobicity) before the surface-applied hydrophobic agents were able to be effective. The hydrophobic character of the base paper depends, among other things, on treatment with internal sizing agents (Hubbe 2007; Ehrhardt and Lecky 2020). Only when the base sheet both had a certain porosity and internal sizing treatment did the surfaceapplied SMA contribute significantly to the water-repellent nature of the product after the size press (Batten 1992).

\section{Attributes of surface-applied hydrophobes affecting their performance}

It will be argued in the next section that the performance of surface-applied hydrophobic agents must depend on rates of diffusion and rates of molecular orientation, etc. The rates of such processes can be expected to depend on molecular mass (Vrentas and Duda 1977). As already noted, Batten $(1992,1995)$ reported that a molecular mass of at least 30,000 to 50,000 was needed to achieve the highest resistance to aqueous fluids. Higher molecular mass did not affect the results. Wang et al. (2019) studied the effects of different molecular mass versions of collagen-based latex products added with starch to the paper surface; no significant effects attributable to molecular mass were apparent 
within the range of study. Garnier et al. (2000) observed surprisingly that lower molecular mass of SMA in aqueous solution gave rise to larger molecular agglomerates.

The ratio of monomeric components has been shown to be very important in specific cases. For example, a higher proportional content of the hydrophobic monomer styrene has been shown to yield additives that confer greater hydrophobicity to paper when added at the size press (Batten 1995; Guo et al. 2012; Yan et al. 2013).

Finally, the ionic form has been found to be critically important, when studying the effects of SMA products. Because the charged groups of SMA are carboxylic acid, the extent of protonation can be controlled by adjusting the $\mathrm{pH}$. With sufficient lowering of $\mathrm{pH}$, the extent of ionic charge would not be enough to keep the molecule in aqueous solution (Ferry et al. 1951). Papermakers know anecdotally that the size press pH may need to be kept above a critical level, to be determined by experience, to achieve efficient runnability with SMA. The ammonium form of SMA has been found to outperform the sodium form in terms of its hydrophobic effect when added with starch at the size press (Batten 1995). By contrast, the sodium form of SMA was found to be more effective for strength improvement (Batten 1995).

\section{MECHANISTIC ISSUES}

\section{Overview}

Delivery of mixtures to the paper surface

The achievement of hydrophobicity of paper, as a result of additives at the size press, can be regarded as a process involving some critical steps. The first such step involves the challenge of delivering a relatively uniform mixture to the paper surface, while at the same time using compounds that have sufficient hydrophobic character to be able to achieve the needed effects. The second step involves some kind of diffusion of the hydrophobic substance to the surface of a starch film, as well as the possibility of its orientation. Fortunately, in facing such a challenge, one can look towards biological systems for guidance. Living organisms are constrained by having to manipulate component molecules in aqueous media, while at the same time constructing a variety of substances that are either highly crystalline (e.g. cellulose) or hydrophobic (e.g. many of the wood extractives). Tolstoguzov $(2003,2004)$ postulated that the detailed structures of polysaccharides played a key role in bringing out the phase separation that led to the first biosynthesis of cellulose and multicellular life. The sections that follow, accordingly, will consider ways in which the structure of starch, and also that of the surface-applied hydrophobic copolymers, may likewise play roles that are important for their mixing and delivery at the paper surface.

Another aspect to consider is the ability of water to solubilize various materials. Blokzijl and Englberts (1993) discussed the hydrophobic effect, which can be defined as the tendency for hydrophobic materials to self-associate in water. Such self-association can lead to the formation of either micelles or interfacial monolayers. In each case, the effects can be mainly explained by a tendency of water to maximize the number of hydrogen bonds in the system. It was noted that water is able to accommodate a moderate amount of some relatively small hydrophobic molecules with only a small penalty of hydrogen bonding. But that capability has its limits, which is consistent with the common observation that various hydrophobic substances tend to come out of aqueous solution once their concentration reaches a threshold. Based on these principles, one can anticipate situations 
in which an aqueous phase may be able to serve as a solubilization medium for a small amount of a hydrophobic substance, but phase separation can be expected when higher amounts are added or if conditions such as temperature or $\mathrm{pH}$ are changed to reduce the solubility.

\section{Lucas-Washburn model}

Many aspects of the permeation of liquids into paper have been effectively modeled and explained based on concepts proposed by Lucas (1918) and Washburn (1921). Applications of their equations to paper products have been considered elsewhere (Hubbe et al. 2020), so only a brief description will be given here. The concept is based on a balance between capillary forces drawing liquid into pores of the paper vs. viscous forces that are resisting the flow of that liquid. In the absence of an applied pressure, the balance of forces leads to the following expression of the extent of penetration $(L)$ as a function of time $(t)$

$$
L=\left[\left(2 r \gamma_{\mathrm{LV}} \cos \theta t\right) /(4 \mu)\right]^{1 / 2}
$$

where $r$ is the effective pore radius (modeled as a cylinder), $\chi_{\mathrm{Lv}}$ is the interfacial tension (liquid to its vapor), $\theta$ is the contact angle (drawn through the liquid phase), $t$ is the elapsed time, and $\mu$ is the dynamic viscosity. It is notable that the distance penetrated into the paper is predicted to be proportional to the square-root of the characteristic pore size and also to the square-root of time.

\section{Development of Hydrophobic Effects}

Wettability characteristics of starch

Based on its functional groups, starch can be regarded as a hydrophilic compound. Each of the anhydroglucose repeating units in the starch molecular structure contains three water-loving hydroxyl groups. One may ask, how can a substance having such a high proportion of water-loving functional groups function effectively in the distribution of hydrophobic agents during a papermaking operation? In this regard, it is important to consider how a solution of starch will be able to participate in two key steps: First it needs to be able to participate in the relatively uniform distribution of a hydrophobic compound during the size press operation. Then it needs to allow the hydrophobic material to position itself so as to confer hydrophobic character to the dried film of starch on the paper.

Because of the detailed orientation of hydroxyl groups in the macromolecule, amylose is able to orient itself in a helical fashion such that it can present different affinity characteristics toward the inside and the outside (Immel and Lichtenthaler 2000). Tolstoguzov $(1999,2003)$ coined the term "molecular mimicry" to describe such capability. This capability is consistent with starch's ability to serve as a medium for the distribution of highly hydrophobic nanoparticles (Chen et al. 2017) and to adsorb onto hydrophobic mineral surfaces (Shrimali et al. 2018).

Some of the best examples showing starch's ability to accommodate hydrophobic solutes can be classed as inclusion complexes (Tolstoguzov 2003). Thus, by forming a Vtype helix, the amylose molecule is able to "pretend" that it is hydrophobic - at least on one of its sides when in the needed conformation. A range of detailed V-complex structures have been identified, and these appear to be related in some cases to the size of the hydrophobic compounds that are hosted (Conde-Petit et al. 2006). Table 4 lists some of the articles describing inclusion complexes involving lipophilic materials within V-type 
amylose helices. As shown, the list of hydrophobic entities within starch inclusion compounds is diverse and extensive, even including linear oligomers of iodine. Starchiodine complexes were discussed in a review dealing with analytical staining (Hubbe et al. 2019). Immel and Lichtenthaler (2000) provide evidence that the presence of lipophilic materials when starch has been freshly cooked tends to favor the formation of $\mathrm{V}$-complexes that are able to accommodate those materials. Otherwise, more of the starch is likely to form other structures, such as double-helix A-complexes, which do not have any capability of accommodating hydrophobic guest molecules.

Table 4. Examples of Inclusion Complexes Formed with Amylose and Hydrophobic Compounds

\begin{tabular}{|l|l|}
\hline Hydrophobic Entity & Citation \\
\hline Fatty acid, iodine & Mikus et al. 1946 \\
\hline L-menthone, a flavor compound & Kuge and Takeo 1968 \\
\hline Menthone, a flavor compound & Rutschmann et al. 1989 \\
\hline Lipids (NMR study) & Morrison et al. 1993 \\
\hline Less complexing ability with hydrophilic substitution of amylose & Wulff et al. 1998 \\
\hline Hydrocarbons (FTIR analysis) & Polaczek et al. 2000 \\
\hline Flavor compounds, e.g. decanal, menthone, geraniol & Kasemwong \& I. 2003 \\
\hline Flavor compounds, e.g. methanone, decanal, thymol & Conde-Petit et al. 2006 \\
\hline Review article & Putseys et al. 2010 \\
\hline Palmitic acid & Meng et al. 2014 \\
\hline Surfactants, e.g. sorbitan monopalmitate & Ortega-Toro et al. 2014 \\
\hline Several phenolic compounds, many of them quite large & Zhu 2015 \\
\hline
\end{tabular}

Another example that shows the dual nature of starch is provided by cyclodextrins (Roy et al. 2015; Hubbe et al. 2021). A cyclodextrin consists of a ring of 5 to 7 anhydroglucose moieties held together by $\alpha$-glycosidic bonds. These rings are able to serve as hosts for hydrophobic entities such as oils.

\section{Solubility parameters}

Computational approaches to predicting the solubility of polymers in different media are typically based on an averaging of group contributions, an approach that generally ignores the possibility that just one side of the molecule may be involved with an interaction of interest. Based on contributions from polar (including hydrogen bonding) and nonpolar (van der Waals) interactions, it is possible to predict the solubility of various compounds in a variety of pure liquids and their mixtures (David and Sincock 1992; Hansen 2007). In general, with increasing molecular weight, polymers tend to become increasingly fussy about what liquids they will dissolve in. Each parameter in the solubility description needs to be a close match to the corresponding value in the solvent, or otherwise a high molecular weight polymer will likely remain undissolved.

The dissolution of monomeric compounds tends to be strongly favored by an increase in entropy of the system (Arzpeyma et al. 2013). In other words, the system becomes more random when two different pure substances become intimately mixed. However, when one is considering macromolecules, the contribution of entropic effects can be strongly repressed (Flory 1942; Kuleznev et al. 1971). That is because each monomeric unit within the chain of a polymer is constrained to remain in a position adjacent to the next monomeric unit. As in the case of a chain-gang composed of prisoners, the chain as a whole has relatively few degrees of freedom. Thus, as noted by Schweizer 
and Singh (1995), the interactions among polymers tend to become dominated by enthalpic considerations. Only if the molecules are able to conform together, achieving a dense structure with strong mutual interactions of various kinds, is solubility favored. Dudowicz et al. (2013) considered the mutual solubility of polymer solutions and blends. Strong temperature dependences were predicted based on thermodynamic calculations. A takeaway from the cited work is that quantitative prediction of mutual solubility of polymers, including such pairs as starch and SMA, still lies beyond present computational capabilities.

An experimental approach has been used in the case of starch blends with various hydrophobic polymers. Godbole et al. (2003) reported excellent mixing of the highly hydrophobic biopolymer poly(3-hyroxybutyrate) with starch. The presence of a single phase was evidenced by there being only a single glass transmission temperature, as detected by differential scanning calorimetry.

In principle, it is possible to adjust the composition of a copolymer so that it achieves optimal miscibility with starch (Miao et al. 2016). Mutual solubility can be favored by a favorable content of nonpolar, polar, and hydrogen bondable groups on each entity, but one can expect major contributions from conformational and packing factors that are not presently predictable. Nevertheless, Slonimskii (1958) predicts, based on thermodynamics and the low entropic contribution to mixing, that binary mixtures of polymers may appear to be in solution, but they are likely to be "microheterogeneous". Due to the very high viscosity of polymer mixtures, they may fail to separate into two phases, even when that is favored by free energy considerations.

\section{Phase separation}

Once the size-press formulation is applied to paper, three things happen that have potential to disturb the state of mixing or solubilization within the starch-rich mixture. First, since the paper entering the size-press nip is hot, the temperature within the film will rise. Second, some of the water, as well as some materials dissolved in the water, will be drawn into the capillary structure of the paper. Depending on the effective size of the pores and also the gel-like character of the size-press formulation, the starch and hydrophobic copolymers may be partly drawn away from the paper surface and into the bulk of the paper. And third, evaporation takes place, decreasing the moisture content of the film.

Polymer mixtures can separate themselves into phases. For example, Chaléat et al. (2012) found that starch-poly(vinyl alcohol) blends were miscible but only to a limited extent. Polymer bends, after being formed by agitation, were found to separate themselves into two phases, each containing a mixture of a major component and a minor component. Such behavior is similar to the complex coacervation often observed when a binary colloidal suspension separates itself into two phases (Veis 2011).

\section{Behavior of the hydrophobic copolymer}

Having considered solubility issues from the perspective of starch, the next step is to consider the solubility behavior of a hydrophobic copolymer such as SMA or SA, etc. A key point to bear in mind is that these copolymers are polyelectrolytes, a fact that explains their solubility in water and accounts for various effects related to viscosity (Dannhauser et al. 1960). The cited authors found that SMA followed typical viscosity relationships expected for polyelectrolytes. These effects were suppressed with decreasing $\mathrm{pH}$, which led to protonation of the carboxylic acid groups and eventually to phase separation due to lack of solubility in water. One can expect wide variations in the $\mathrm{pH}$ 
conditions employed in different industry-scale size press operations. A near-neutral $\mathrm{pH}$ (e.g. $6<\mathrm{pH}<8$ ) can be expected when typical starch products are cooked with plain water (Latta 1994; Brungardt 1997). Various hydrophobic additives for the size press are formulated with different $\mathrm{pH}$ values, often in the range $4<\mathrm{pH}<8.5$ (Moutinho et al. 2011). Small amounts of such additives as sulfuric acid or sodium hydroxide can be used for $\mathrm{pH}$ control, usually based on the recommended running $\mathrm{pH}$ for the hydrophobic copolymer that is being used. In addition, the $\mathrm{pH}$ condition of the base-sheet can affect the $\mathrm{pH}$ of the size-press solution, especially in cases where excess starch from a size press is circulated back to the starch run tank (Tompkins et al. 1990; Klass 1990). The presence of calcium carbonate in the base paper will tend to increase the $\mathrm{pH}$ of size-press starch (to a $\mathrm{pH}$ of about 7 or 8 ), whereas aluminum sulfate in the base paper will tend to decrease the $\mathrm{pH}$ of the size-press starch (possibly to a $\mathrm{pH}$ of about 5), if not otherwise controlled.

Ferry et al. (1951) proposed that SMA exists in aqueous solution, at least in part, as pairs of macromolecules, with their styrene groups self-associating. This concept was developed further by Garnier et al. (2000), who envisioned a zipper-like self-association of pairs of SMA molecules, as illustrated in Fig. 5. The fact that such a structure allows the water-loving carboxylate groups to face outward provides an explanation for its solubility in water. The last-cited authors proposed that the pair-wise association persists even after a starch-rich aqueous film has dried at the surface of paper.

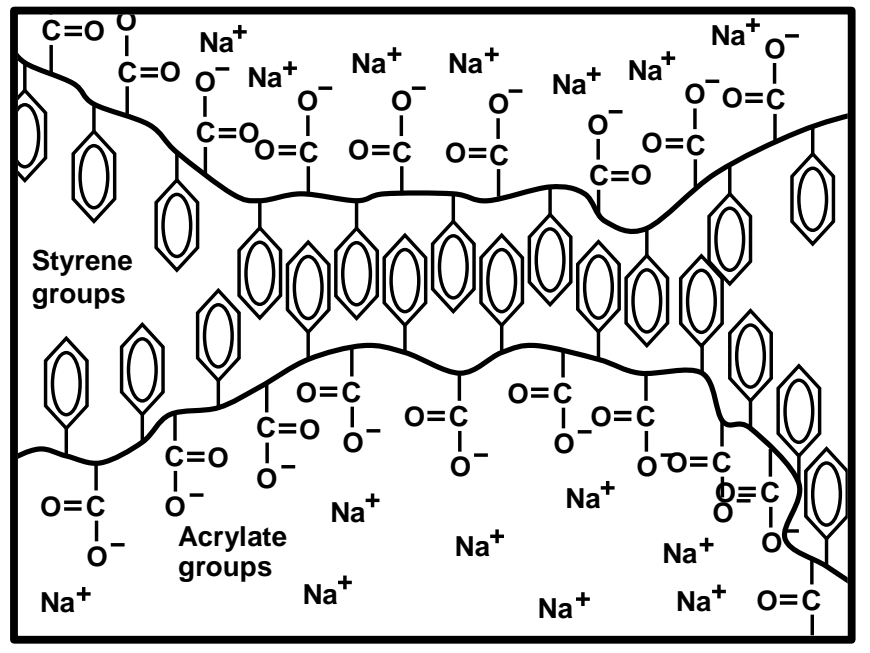

Fig. 5. Schematic diagram of proposed pair-wise self-association of SMA molecules in aqueous mixtures. Figure inspired by Garnier et al. (2000), with some new element incorporated

\section{Breakdown of starch-hydrophobe complexes}

There is evidence that associations between starch and hydrophobic compounds will break down when the systems are heated (Hahn and Hood 1987). The cited authors observed that the ability of corn starch to bind lipids decreased as the temperature was raised in a range from 20 to $60{ }^{\circ} \mathrm{C}$. Such a trend suggests that the V-complex structures responsible for stabilizing of lipophilic compounds in the starch mixture were being disrupted, causing the lipids to be released from the starch molecules. Kasemwong and Itthisoponkul (2013) likewise predicted that complexes can be made to release their contents by changes in moisture content or temperature.

According to Koningsveld (1994), polymer blends are susceptible to gradual changes, which are driven by decreases in Gibbs free energy. In some cases the systems 
show persistent mutual solubility, even in cases where the blends are expected to be immiscible based on differing solubility attributes. In other cases, the mixtures gradually separate from a meta-stable mixture into two phases.

\section{Migration of hydrophobic entities to interfaces}

The increasing hydrophobicity of certain paper products with the passage of time has been attributed to migration of hydrophobic molecules to the surface (Swanson and Cordingly 1959). Such a trend is consistent with the thermodynamic advantage of having a low free energy of the surface in contact with the air. Consistent with this principle, Garnier et al. (2002) proposed the migration of SMA molecules to the surface of starch films during the process of drying. They envisioned that the SMA might remain as the self-associated pairs even after migration to the surface. Further evidence to support such migration was presented by Kopacic et al. (2018), who studied the addition of technical lignin by size-press addition. Surprisingly, greater hydrophobicity was achieved when the lignin was added together with starch, which is more hydrophilic than lignin. The effect is consistent with migration of lignin to the surface, as well as a role of the starch in anchoring it there. Likewise, Mešić et al. (2004) observed increasingly hydrophobic character of films of hydrophobically modified potato starch with increasing temperature of application. Presumably the higher temperatures would promote the diffusion process. Yasuda et al. (1995) demonstrated essentially the same principle, but going in the opposite direction, by first drying a perfluorinated ether compound in the presence of air. The dried surface had very low energy and no oxygen could be detected by X-ray photoelectron spectroscopy. By contrast, after equilibration with high-purity water, the surface was more wettable, and oxygen atoms were found to have migrated to the surface of the film.

\section{Molecular orientation}

The next step is to achieve molecular orientation. According to Davison (1975), the orientation of hydrophobic groups, such as those of rosin and alkylketene dimer, is essential for achieving hydrophobic effects when the agent is added to the fiber slurry. Likewise, it has been proposed that the hydrophobic effect of SMA and related molecules at the paper surface is due to the orientation of styrene molecules facing outward from the surface of the starch film (Hubbe 2007). This mechanism is consistent with a gradual decay of hydrophobicity observed by Garrett and Lee (1998) when forming SMA films on glass in the absence of presence of starch. The initial contact angles were relatively high, especially when applied in the presence of starch. But the contact angles gradually decreased with the passage of time in contact, indicating increased wettability. Such results suggest that the orientation of molecules at the surface is able to change with time to be more consistent with an adjacent phase, which may be an aqueous phase.

\section{Starch appearing to serve as an anchor}

In order for oriented molecules at a surface to produce a significant hydrophobizing effect, they need to be anchored securely in place. This principle helps to explain why, for instance, simple paraffin oils are not efficient for imparting water resistance to paper. The previous subsection included two examples in which mixtures of starch and a hydrophobic compound gave a greater hydrophobic effect than in the absence of starch (Garrett and Lee 1998; Kopacic et al. 2018). This raises the question of whether starch may be serving as an anchoring medium for the hydrophobic polymers at the film surface. This question has not been well answered in published articles. However, a clue is provided by the work of 
Chen et al. (2017). These investigators first prepared a wet film of starch, then spraycoated the starch with an alcohol suspension of highly hydrophobic nanoparticles. When the film had been dried, it exhibited superhydrophobicity, in addition to scratch-resistance and permanence of the hydrophobic effect. Such behavior is consistent with effective interactions between the starch and the highly hydrophobic surfaces.

In the case of a size-press hydrophobic agent such as SMA or SA, any orientation that favors exposure of hydrophobic styrene groups facing the air phase can be expected to result in a greater share of the hydrophilic carboxylic groups (from the maleic acid moiety or the acrylic acid moiety) facing inwards, towards the starch. Such a viewpoint is depicted in Fig. 6, which is based on the concept of styrene group self-association. Though certain hydrophobic aspects of starch, in certain molecular conformations, have been emphasized in this article, there is no doubt regarding starch's predominantly hydrophilic nature. That nature is shown, for instance by the fact that starch needs to be rendered more hydrophobic to be use as an effective filler in various synthetic plastics (Rahmat et al. 2009).

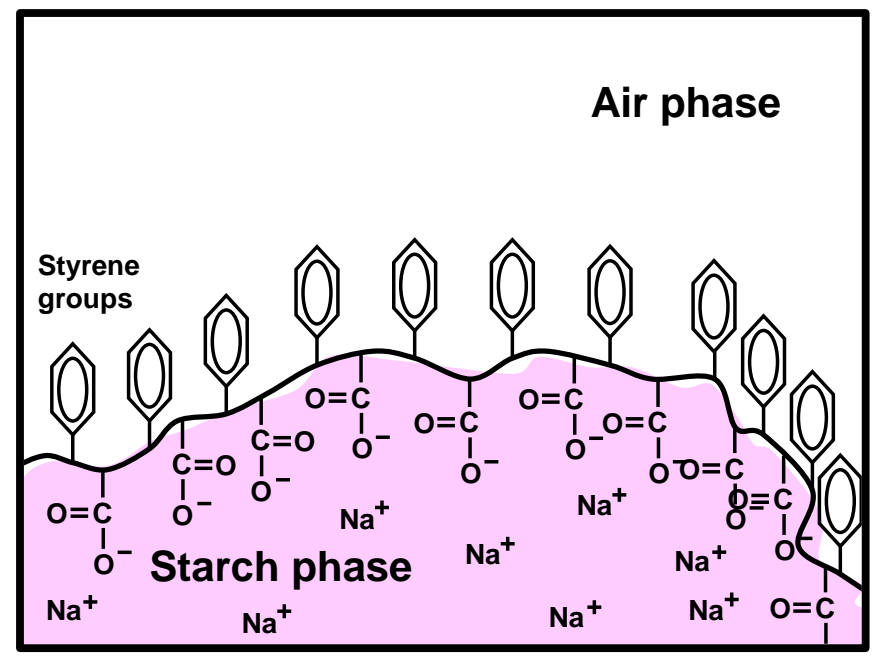

Fig. 6. Concept of SMA or SA having migrated to the surface of a starch film, where it becomes oriented with the oleophilic groups facing outwards in the process of drying

\section{Anchoring by ionic interactions}

Though it does not appear to be common practice, there is evidence that aluminum sulfate (alum) can be used as a means to anchor hydrophobic copolymers for surface sizing, thus increasing their effectiveness. For example, Batten (1992) and Proverb (1999) reported that aluminum sulfate present in the base sheet interacted with the carboxylate groups of SMA or SA, respectively, thereby helping to anchor such copolymers at the paper surface. Takaki et al. (1997) reported similar beneficial effects of alum in the base sheet when adding a long-chain alkyl derivative of acrylic acid at the size press. Dong et al. (2015) achieved a similar sizing enhancement by adding alum directly with fatty acids salts at the size press. A closely related sizing effect was achieved by adding a combination of black liquor and alum at the size press (Han and Cho 2016). Weak black liquor contains such wood resins as rosin and fatty acids (Back and Allen 2000). Wang et al. (1997) showed that SMAs can be used as hydrophobic agents for wet-end addition in cases where alum was also being added.

Related anchoring effects have been proposed when cationic hydrophobic copolymers are used in combination with oxidized starch added to the paper surface. Such 
a mechanism was shown schematically by Bung (2004). Iselau et al. (2015) showed much greater hydrophobic character when using cationically charged hydrophobic latex particles with starch at the size press with oxidized starch, rather than amphoteric or negatively charged latex of otherwise similar nature. As was noted earlier, a great many of the more recently reported hydrophobic latex products intended for size-press hydrophobization of paper have been prepared with cationic monomers included (Sackmann et al. 1986; Schurmann et al. 1989; Bung et al. 1992; Ono and Deng 1997; Yang and Deng 2000; Jonhed and Jarnstrom 2009; Inaoka et al. 2011; Cui and Jing 2012; Yan et al. 2013; Sodeyama et al. 2014; Stankovska et al. 2014; Iselau 2015, 2017, 2018; Özdemir et al. 2017b). Xu and Hu (2012) employed an opposite approach by using regular anionic latex in the presence of a solution of cationic size press starch.

\section{Chemical effects}

Some of the most promising means of achieving anchoring of hydrophobic agents at the surface of a starch film involve chemical effects. The best-known example involves the usage of the ammonium salt of SMA. This agent has been found to impart greater hydrophobicity in comparison to similar SMA that was formulated with the sodium counter-ion (Batten 1995). The enhanced sizing effect has been explained as being due to the flashing off of ammonia gas in the course of drying of the starch film (Batten 1992, 1995). Because ammonia is alkaline, its departure results in a lowering of the $\mathrm{pH}$ associated with the film. An expected consequence is greater protonation of the SMA, leading to greater hydrophobic character (Cushing 1979). Indeed, titrations by Ferry (1951) show that the two adjacent carboxylic acid groups on SMA have strikingly different levels of acidity, as reflected in their respective $\mathrm{p} K_{\mathrm{a}}$ values. Garnier et al. (2000) reported remarkable increases in hydrophobicity when the $\mathrm{pH}$ of SMA mixtures was decreased in the range from 12.5 to about 3 .

Parallel effects were demonstrated in a system where the signs of charges were reversed; thus, Fanta et al. (2017) showed effective surface sizing when long-chain amines were applied to paper as a starch solution. Presumably the hydrophobic compounds were being stabilized as inclusion complexes in V-complexes of amylose. After application of the starch solution, sodium hydroxide was applied to deprotonate the amine groups, thus neutralizing their charges. As a result, the compounds, being neutral in charge, had a greater hydrophobic character.

\section{Effects of Starch and Hydrophobic Copolymers on Paper's Porosity}

The foregoing discussion has emphasized the role of both starch and hydrophobic copolymers in the delivering of low surface energy groups to the surface of a film on the treated paper. But another issue needs to be considered. As evident from the earlier discussion of the Lucas-Washburn equation, the management of the porosity of the paper is another important tool at the disposal of papermakers for resisting penetration by aqueous fluids. It is reasonable to expect that the formulation of size-press solutions can have a bearing on the sizes and frequency of pores that are still accessible at the paper surface after the size press.

Before considering size-press variables, it is important to recall that base-sheet properties - including the porosity - can have a major influence on the water-resistant performance of the resulting paper (Batten 1992; Aloi et al. 2001). The main tool that papermakers have used to adjust the porosity of paper made from kraft pulp, as a means of optimizing size press operations, is mechanical refining. The concepts and equipment used 
in refining have been reviewed (Gharehkhani et al. 20015). The internal delamination of fibers, which results from refining, allows the fibers to conform to each other more tightly, forming a denser sheet of paper that is less porous. If yet more blockage of pores is needed, especially if there is a simultaneous goal to minimized the densification of the paper, then two types of additive can be considered. Some additional strategies can be used, if yet higher resistance to flow into the paper is needed, especially if there is a need to limit the degree of densification of the paper. For instance, porosity can be reduced by using delaminated or fine kaolin clay as a filler (Velho and Gomes 1995). More recently it has been found that paper tends to be much less permeable to air if it has been prepared with nanofibrillated cellulose (Salas et al. 2019).

\section{Size press starch parameters}

In principle, an additive to size-press starch might contribute greatly to blocking passage of liquid into the sheet if it can improve the integrity of the starch film. For such an effect to be achieved, the starch film would need to remain near the surface of the paper, thus helping to seal the paper surface. In other words, the immobilization of a size-press formulation after it is applied would need to be sufficiently rapid so that the material would not just be drawn into the porosity of the paper.

Inaoka et al. (2011) claimed the concept of a surface sizing treatment that raised the challenge still further. They proposed to use the size press to hydrophobically size ordinary paper sheets that had not been internally sized. In other words, no rosin, ASA, or AKD had been added at the wet end during formation of the base sheet. Likewise, Singh et al. (2010) claimed a system in which low internal sizing treatment was combined with high surface sizing treatment, including the use of a high viscosity solution. These claims are contrary to the findings of Brungardt (1997), who concluded that the internal size AKD can play a dominant role in the overall hydrophobic treatment of the paper, even being able to react with starch added at the size press. The cited author observed that the effect of the AKD was larger than that of the hydrophobic compound added at the size press in the cases considered.

Aqueous pigment coatings applied to paper, when suitably formulated, are able to immobilize sufficiently rapidly after their application of paper that it may not matter much whether or not the base sheet has been internally sized (Triantafillopoulos 1996). Solids contents of such coatings can be in the range of $60 \%$ to $70 \%$, which is much higher than typical size press formulations. Thus, part of the answer may lie in the further development of size-press equipment to allow higher starch solids. Film-press equipment, including blade-metering size presses, make it possible to apply starch films to paper at higher solids and greater uniformity (Klass 1990; Rennes 1998). In addition, blade coater application of size-press starch has been well established as a viable approach (Fineman and Hoc 1978; Klass 1988). A further strategy to increase the immobilization tendency of starch films might involve the incorporation of nanofibrillated cellulose into the size-press formulation (Dimic-Misic et al. 2013; Hubbe et al. 2017). As noted in the cited authors, the nanocellulose can greatly increase the thixotropic nature of the mixture. This is an area of technology that has a lot of potential, but it still has considerable challenges ahead. 


\section{CONSIDERATION OF THE HYPOTHESIS STATEMENTS}

This section considers the three hypothesis statements that had been introduced in the Introduction. Table 5 lists the three statements, together with a general assessment of the validity of those statements based on the literature cited in this article. Key literature citations, related to supporting the hypothesis statements, are listed as well. In general, all three of the hypothesis were found to be supported by theoretical work. However, in each case there appear to be opportunities for high-level academic research to further show to what degree the proposed hypotheses are the best explanations for what happens in industrial hydrophobic surface-sizing of paper. From a practical perspective, it is always important to keep in mind that successful industrial implementation often does not need to wait for all the theoretical questions to be addressed.

Table 5. Hypothesis Statements and their Assessments of their Validity Based on the Reviewed Literature

\begin{tabular}{|l|l|l|}
\hline Hypothesis Statements & Assessments of Validity & Citations \\
\hline $\begin{array}{l}\text { Synergism between hydrophobic } \\
\text { copolymers and starch, related to } \\
\text { the differing character of different } \\
\text { sides of amylose macromolecules, } \\
\text { makes it possible to distribute the } \\
\text { hydrophobic substance during } \\
\text { preparation of the mixture to be } \\
\text { used at a size press. }\end{array}$ & $\begin{array}{l}\text { The behavior of VH-type starch } \\
\text { crystals, by the example of } \\
\text { cyclodextrins, by the effectiveness } \\
\text { of starch in aiding distribution of } \\
\text { hydrophobic agents, and by the } \\
\text { ability of starch to adsorb onto } \\
\text { hydrophobic mineral surfaces. }\end{array}$ & $\begin{array}{l}\text { Roy et al. 2015; } \\
\text { Chen et al. 2017; } \\
\text { Shrimali et al. 2018 }\end{array}$ \\
\hline $\begin{array}{l}\text { A degree of self-association of the } \\
\text { hydrophobic copolymers also } \\
\text { plays a role in the distribution of } \\
\text { the mixture of starch and } \\
\text { hydrophobic copolymer. }\end{array}$ & $\begin{array}{l}\text { Though this hypothesis appears } \\
\text { consistent with the literature, it is } \\
\text { hard to find direct support. More } \\
\text { research related to the mechanism } \\
\text { of solubilization of amphiphilic } \\
\text { agents would be helpful. }\end{array}$ & $\begin{array}{l}\text { Ferry et al. 1951; } \\
\text { Garnier et al. 2000; }\end{array}$ \\
\hline $\begin{array}{l}\text { Phase separation during the drying } \\
\text { of a mixture of starch and } \\
\text { hydrophobic copolymer plays a } \\
\text { role in the development of a } \\
\text { hydrophobicity at the paper } \\
\text { surface. }\end{array}$ & $\begin{array}{l}\text { upon heating of starch solutions } \\
\text { have been well established, but } \\
\text { there is a need for systematic } \\
\text { research that is more directly } \\
\text { related to paper hydrophobization. }\end{array}$ & $\begin{array}{l}\text { Hahn and Hood } \\
1987 ; \text { Tolstoguzov } \\
2003,2004 ; \text { Veis } \\
2011 ; \text { Chaléat et al. } \\
2012\end{array}$ \\
\hline
\end{tabular}

\section{IMPLICATIONS FOR FUTURE DEVELOPMENTS}

In this final section of the article, four lines of potential future developments will be considered, related to the application of hydrophobic copolymers at the size press of a paper machine. The first of these is to consider what can be achieved by laboratory research. Second, attention is paid to a certain kind of research - molecular dynamics simulations - which seems well suited for answering some yet-unanswered questions about how the hydrophobic agents behave at a nano-scale during evaporative drying of a starch film. Third, there is a need for kinetic analysis and modeling, examining the competitive rates that affect migration, orientation, and anchoring effects of hydrophobic polymers within and on a starch film. Finally, there appear to be fertile grounds for further development of the application technologies so that hydrophobic effects can be achieved more reliably and efficiently in the manufacturing facility. 


\section{Laboratory Research}

Phase behavior

As was noted earlier, various evidence suggests that hydrophobic copolymers in an aqueous mixture may self-associate (Ferry et al. 1951; Blokzijl and Englberts 1993; Garnier et al. 2000). On the other hand, one might propose that the hydrophobic compounds could be individually stabilized in V-complexes involving amylose molecules (Immel and Lichtenthaler 2000; Conde-Petit et al. 2006). As a third alternative, one might envision that the hydrophobic compounds are present as micelles, i.e. groups of multiple molecules that are arranged with a predominantly hydrophobic core and a predominantly hydrophilic exterior (Yang et al. 2015). The cited article raises the concept that hydrophobically modified starch, for example, could arrange itself in solution in a micellar form. Such possibilities can be investigated by experimentation. For example, light scattering methods can be used to determine the size of any micelles in solution (Finsy 1994). Fluorescent dyes that are specific to hydrophobic substances (Baba et al. 2009; Reisch and Klymchenko 2016) could be used to reveal the distribution of such groups in a starch-based film. The resulting films could be inspected by confocal laser scanning microscopy.

\section{Rheology}

The viscoelastic properties of formulated mixtures of dissolved starch and hydrophobic copolymers can be expected to control the degree to which the material remains near to the surface of the paper, especially in cases where the base paper is porous and hydrophilic. Because the total solids of solutions used at the size press are generally much lower (e.g. 5 to 20\%) than those employed in the pigmented coating of paper (e.g. 50 to $70 \%$ ), one can expect a much greater tendency for the material to penetrate into the bulk of the paper sheet, which will reduce any contribution of hydrophobic agents. To overcome this tendency, one strategy can be to employ mixtures exhibiting a gelation tendency. In other words, associations among the starch and other polymers in the mixture need to associate, forming a hydrogel structure (Song et al. 2009; Stanescu et al. 2011). In principle this can be achieved in two ways. First, one could modify the starch used at the size press by incorporation of pendant hydrophobic groups, which would be able to form reversible associations with the styrene groups of such copolymers as SMA and SA (Zhang 2001). Second, one could employ oppositely charged starch and hydrophobic components, e.g. oxidized starch with a cationic latex (Bung 2004; Iselau 2015). However, due to the relatively low solids content of typical size press solutions, it is not clear whether or not the strategies just mentioned would be sufficient to reach the targeted level of hold-out at the paper surface. A third option consists of using cationic starch at the size press (Lee $e t$ al. 2002). Possibly because its charge is opposite to that of typical papermaking fibers, the cationic starch has a greater tendency to remain near the paper's surface when applied as a size press. In recent work by the same group, Seo et al. (2020) showed that the penetration of oxidized starch into paper at the size press could be decreased by pre-mixing it with cationic acrylamide copolymer. Furthermore, as was noted earlier, an emerging technology to achieve higher viscosity and a gelation tendency in aqueous coatings for paper involves the use of nanofibrillated cellulose (Dimic-Misic et al. 2013; Hubbe et al. 2017). Such mixtures exhibit a strong shear-thinning tendency, which can be regarded as

favorable for size-press operations. However, it is important to run trials on the industrial equipment to confirm that a given formulation is suitable for the paper machine speeds, solids levels, and other parameters characterizing the operation. 


\section{Migration}

If the starch and hydrophobic copolymer applied to paper at a size press were to remain as a highly uniform mixture, then the contribution to any hydrophobic effect would be minor. That expectation follows from the much lesser content of the hydrophobic copolymer in comparison to starch in typical cases. Thermodynamics favors the migration of lower-energy chemical groups to the surface of a film that is in contact with air (Mortazavi and Nosonovsky 2012; Reinke et al. 2015). However, there can be uncertainty regarding whether the molecules within the film have had sufficient time and ability to move in order to achieve significant migration. Fortunately, once again, there are methods that can be used to demonstrate the presence of chemical groups in the outermost surface layers of solids. In particular, this can be achieved with use of time-of-flight secondary ion mass spectrometry (ToF-SIMS) (Belu et al. 2003). This method has been used in the past, for instance, to show the presence of substances at the surface of paper that interfered with the performance of alkenylsuccinic anhydride (ASA) sizing treatment (Brinen and Kulick 1994).

\section{Molecular orientation and wettability}

Contact angle tests can be used to reveal the extent to which hydrophobic groups are exposed at the surface of a starch-based film (Garrett and Lee 1998; Andersson et al. 2008; Anttila et al. 2012; Gigac et al. 2014; Iselau et al. 2015; Wang and Fang 2016; Özdemir et al. 2017a,b). By carrying out such tests with both water droplets and diiodomethane, it would be possible to show evidence of the effect of styrene groups in increasing the dispersion component of free energy at the surface (Moutinho et al. 2011). Information from such tests also can be backed up by inspecting wavelength shifts of infrared spectra; for instance, such shifts could confirm the existence of association among adjacent styrene aromatic groups or hydrogen bonding interactions (Mikhaylova et al. 2006; Bonechi et al. 2008).

\section{Suitability for particular applications of paper}

Laboratory work also will be continually helpful as a way to answer questions about the suitability of hydrophobic additives for different grades of paper. As was noted by Shreier (1997), a variety of different hydrophobic treatment agents and schemes are needed in order to meet the contrasting requirements faced by different papermakers. Up to this point the main usage of hydrophobic additives to the size-press have been in printing grades. In view of the increased printing of packaging paper and paperboard grades - for instance for point-of-sale containers, which serve for both shipping and display - one can envision implementation of this type of technology in various pre-printed packages. Packages that require resistance against water vapor, oxygen, or grease also seem the be good candidates, since barrier layers often incorporate starch and/or hydrophobic treatments (Ferrer et al. 2016; Hubbe and Pruszynski 2020).

\section{Molecular Dynamics Simulations}

The topic of molecular dynamics (MD) simulation is worth emphasizing here due to its unique characteristics. Unlike the approaches just described, it is possible to do the entire MD analysis by computer. The challenge is to define suitable boundary conditions and assumptions about the interactions among the molecules. MD simulations become increasingly challenging as the molecular mass of the materials is increased. Though the power of available computers has rapidly increased, it is still necessary to make simplifying 
assumptions and approximations, which can affect the user's confidence in the answers. An example of such a simulation is provided by Xue et al. (2018), who showed how SMA molecules can arrange themselves at the surface of proteins. The interaction appeared to be driven by the hydrophobic effect, as mentioned earlier (Blokzijl and Englberts 1993; Anttila et al. 2012). MD simulations have been used effectively to study the design of proteins and their wettability (Childers and Daggett 2017). Also, MD simulations have been used to model the transformation of helical polymer structures to crystalline polymer structures (Yamamoto et al. 2005).

\section{Kinetic Issues}

There are aspects of the mechanism of surface hydrophobization in starch mixtures that are likely to involve competition between different concurrent processes. For instance, an SMA chain may be simultaneously undergoing a self-association equilibration, diffusing in the bulk of solution, orienting itself relative to adjacent hydrophilic or hydrophobic entities, and ultimately orienting itself at the surface. It is likely that none of these interactions involve covalent bonding. Often it can be a challenge to match realistic mechanistic models of a process so as to be able to explain overall rates. One can envision experiments in which the liquid in contact with a surface is abruptly changed, and one evaluates the rate at which the wettability of the surface changes as a response (Yasuda et al. 1995). Also, one could evaluate the effects of factors such as temperature and molecular mass that might influence rates of development of hydrophobicity at surfaces. Since changes in temperature often cause different rates of drying, one can envision experiments in which highly humid conditions or increased atmospheric pressure are employed as a means of keeping the overall drying rate constant in a series of tests.

\section{Developmental Opportunities}

Coordination with jet cooking

The processing industries are continually looking for ways to adjust their processes, equipment, and related control technologies to achieve higher efficiency. In past decades the industry has generally moved away from batch cooking of starch and into continuous cooking, which is sometimes called jet cooking (Rankin et al. 1976). There is some evidence to suggest that the jet cooking or starch may offer some advantages in terms of the formation of V-complexes that can serve as hosts for hydrophobic compounds. In particular, it has been found that changes in the crystal form of starch can begin to happen soon after the initial gelatinization of the starch (Andersson et al. 2008). In principle, if a hydrophobic agent is added either before or immediately after the starch has been gelatinized, the presence of the hydrophobic compound will favor the development of the V-complexes, which also will be acting to as hosts to stabilize the hydrophobic compound in the starch mixture (Immel and Lichtenthaler 2000). One can envision a series of tests to optimize this part of the process, in addition to studying effects related to subsequent steps such as migration to the surface and release of hydrophobic compounds from the starch complexes.

\section{Higher starch molecular mass}

One of the inherent features of size-press application of starch is that the starch generally needs to have been reduced in viscosity to flow adequately during application in various size-press nip configurations. However, by use of different equipment it has been possible to increase the viscosity of the starch solution and still achieve good runnability 
(Klass 1988, 1990; Lipponen et al. 2005). In principle, a starch product that has been excessively decreased in molecular mass will have less potential to contribute to strength in a paper product (vanSoest et al. 1996). But there has been a lack of study to determine whether there is an optimum molecular mass of starch that will be most suitable in terms of hydrophobization at the size press.

\section{Green chemistry}

Though SMA and SA copolymers generally have displayed favorable properties, allowing them to become widely implemented in the paper industry, these products are prepared from petroleum-derived monomers. Surface sizing with natural-based hydrophobic agents has been considered in a minority of reported studies (Dong et al. 2015; Han and Cho 2016; Kopacic et al. 2018). The cited studies all involved the use of lignin, which bears a rough resemblance to SMA and SA, since it has hydrophobic aromatic groups. Lignin is available at low cost and in very large quantities at pulp mills throughout the world. Key challenges with respect to using lignin as the basis for chemical preparation have been related to its complex, irregular molecular structure, as well as expected variability in composition and molecular mass when comparing different days or different locations. One might argue that the hydrophobization of paper's surface might be a more forgiving application compared to some other potential applications for lignin. Such questions might require considerable developmental research to answer.

Another polymer worthy of consideration in future studies of surface sizing and hydrophobicity is chitosan. Like starch, chitosan is obtained from renewable resources (e.g. crab shells). Chitosan has been used for surface-sizing or coating of paper, leading to products with improved properties (Lertsutthiwong et al. 2004; Kjellgren et al. 2006; Fernandes et al. 2010). Unlike native starch, chitosan has a positive ionic charge, which might give it favorable performance as a size-press additive. In addition, dried chitosan films are known to have a hydrophobic character (Cunha et al. 2008; Hubbe 2019).

\section{CLOSING COMMENTS}

Based on the publications considered in this article, one can conclude that the addition of hydrophobic copolymers at the size press of paper machines fills an important need related to paper products, especially in the domain of printing papers. Some factors that appear to be important, to achieve favorable results, include a balance of hydrophobic and hydrophilic parts of the molecule, a sufficient molecular mass, and addition to a starch solution. Evidence is consistent with a process in which the hydrophobic material is stabilized by the presence of starch molecules, taking advantage of the ability of amylose to present hydrophobic character within certain helical structures, etc. Also, the published findings are consistent with a process whereby the hydrophobic copolymers migrate, at least to a partial degree, so that they are enriched at the air interface by the time that the film of starch has dried by evaporation during the papermaking process. However, the amount of academic research devoted to this area of technology has been limited. Thus, many mechanistic questions are still in need of careful study to nail down the mechanisms in a more convincing way. Also, there appear to be rich opportunities for further developments related to efficient processing and distribution of the hydrophobic additives at the paper surface in paper production facilities. 
Regarding the three hypotheses introduced near the start of this article, the findings are mixed. Abundant, but often indirect support can be found suggesting that the amylose component of typical starch in aqueous solution has a strong ability to stabilize hydrophobic compounds. The second hypothesis involved a proposed pair-wise association between macromolecules of styrene maleic anhydride or related compounds; though this hypothesis is supported by light scattering results and contact angle tests (Garnier et al. 2000), further study is recommended. The third hypothesis proposed that heating and evaporative drying of a starch film might induce phase separation and thereby promote migration of hydrophobic copolymers to the air-starch interface. Though this explanation does not appear to conflict with reported findings, it is waiting for definitive experiments to more fully test its validity for systems of interest to papermakers.

\section{ACKNOWLEDGEMENTS}

The authors gratefully acknowledge support from The Scientific and Technical Research Council of Turkey (TUBITAK) who sponsored a planned six-month visit of Dr. Ahsen Bildik Dal to North Carolina State University. The authors also acknowledge the Buckman Foundation for the endowment support of Dr. Hubbe's work. The authors greatly appreciate the help of the following volunteers who studied an earlier version of this article and made suggestions and corrections: Isabel Teixeira Moutinho, Sonae Arauco, Portugal; Öznur Özden, Faculty of Forestry, University of Istanbul-Cerrahpasa; and Hak Lae Lee, Department of Agriculture, Forestry and Bioresources, College of Agriculture and Life Sciences, Seoul National University.

\section{REFERENCES CITED}

Ai, Y., and Jane, J. L. (2015). "Gelatinization and rheological properties of starch," StarchStärke 67(3-4), 213-224. DOI: 10.1002/star.201400201

Aloi, F., Trksak, R. M., and Mackewicz, V. (2001). "The effect of base sheet properties and wet end chemistry on surface-sized paper," TAPPI Papermakers Conf., 2p. 1.

Anderson, J. (1997). "Surface sizing," in: Surface Application of Paper Chemicals, J. Brander and I. Thorn (eds.), Springer Science \& Business Media, London, pp. 138155. DOI: $10.1007 / 978-94-009-1457-5 \_8$

Andersson, C., Jonhed, A., and Jarnstrom, L. (2008). "Composition and film properties of temperature responsive, hydrophobically modified potato starch," Starch-Stärke 60(10), 539-550. DOI: 10.1002/star.200800216

Anttila, M., Kataja, K., Kela, L., Hyvärinen, S., Lampinen, H., and Toivakka, M. (2012). "The self-organization of starch on paper," Nordic Pulp Paper Res. J. 27(3), 621-630. DOI: 10.3183/npprj-2012-27-03-p621-630

Arzpeyma, G., Gheribi, A. E., and Medraj, M. (2013). "On the prediction of Gibbs free energy of mixing of binary liquid alloys," J. Chem. Thermodyn. 57, 82-91. DOI: 10.1016/j.jct.2012.07.020

Baba, K., Kasai, H., Masuhara, A., Oikawa, H., and Nakanishi, H. (2009). “Organic solvent-free fluorescence confocal imaging of living cells using pure nanocrystal forms of fluorescent dyes," Japanese J. Appl. Phys. 48(11), article no. 117002. DOI: 10.1143/JJAP.48.117002 
Back, E. L., and Allen, L. H., (eds.) (2000). Pitch Control, Wood Resin and Deresination, TAPPI Press, Atlanta, GA, 392 pp.

Barker, L. J., Proverb, R. J., Brevard, W., Vazquez, I. J., dePierne, O. S., and Wasser, R. B. (1994). "Surface absorption characteristics of ASA paper: Influence of surface treatment on wetting dynamics of ink-jet ink," TAPPI 1994 Papermakers Conference Proceedings. Atlanta, pp. 393-398.

Batten, G. L. (1992). “A papermakers guide to synthetic surface sizing agents,” TAPPI 1992 Papermakers Conference, TAPPI Press, Atlanta, pp. 12-20.

Batten, G. L. (1995). "Effects of SMA surface sizes on paper end-use properties," TAPPI J. 78(1), 142-146.

Belu, A. M., Graham, D. J., and Castner, D. G. (2003). "Time-of-flight secondary ion mass spectrometry: Techniques and applications for the characterization of biomaterial surfaces," Biomater. 24(21), 3635-3653. DOI: 10.1016/S01429612(03)00159-5

BeMiller, J. N. (2009). "Starch in the paper industry," in: Starch: Chemistry and Technology, Third Ed., J. N. BeMiller and R. L. Whistler (eds.), Elsevier Science, London, Ch. 18.

Bildik Dal, A. E., Hubbe, M. A., Pal, L., and Gule, M. E. (2020). "Crude wood rosin and its derivatives as hydrophobic surface treatment additives for paper and packaging," ACS Omega 5(49), 31559-31566. DOI: 10.1021/acsomega.0c03610

Blokzijl, W., and Englberts, J. B. F. N. (1993). "Hydrophobic effects, opinion and facts," Angew. Chem. 105, 1610-1624; Angew. Chem. Int. Ed. Engl. 32, 1545-1559. DOI: 10.1002/anie.199315451

Bonechi, C., Martini, S., Magnani, A., and Rossi, C. (2008). "Stacking interaction study of trans-resveratrol (trans-3,5,4'-trihydroxystilbene) in solution by nuclear magnetic resonance and Fourier transform infrared spectroscopy," Magnetic Reson. Chem. 46(7), 625-629. DOI: 10.1002/mrc. 2217

Brinen, J. S., and Kulick, R. J. (1994). "SIMS imaging of paper surfaces. Part 4. The detection of desizing agents on hard-to-size paper surfaces," Int. J. Mass Spec. Ion Process. 143, 177-190. DOI: 10.1016/0168-1176(94)04137-V

Brogly, D. A. (1978). "Thermal-chemical starch conversion for size-press application," TAPPI J. 61(4), 43-45.

Brungardt, B. (1997). "Improving the efficiency of internal and surface sizing agents," Pulp \& Paper Canada 98(12), 152-155.

Bung, J. (2004). "Surface sizing agents," IPPTA: Quarterly J. Indian Pulp Paper Techn. Assoc. 16(3), 29-44.

Bung, J., Ulubay, H., and Schutzius, B. (1992). "Paper sizing agents containing cationic dispersants," U.S. Patent No. 5,116,924.

Buttrick, W. G., Ritson, D. D., and Floyd, C. W. (1990). "Improving water resistance of starch coatings," in: Starch and Starch Products in Paper Coating, R. L. Kearney, and H. W. Maurer (eds.), TAPPI Press, Atlanta, pp. 165-198.

Carceller, R., and Juppo, A. (2004). "New surface size composition changes paper surface properties for improving inkjet printability of copy paper," Paperi Рии 86(3): 161-163. 
Cave, L. E., and Adams, F. B. (1968). "Continuous enzyme conversion of starch for paper surface treatment," TAPPI J. 51(11), 109.

Chakar, F. S., and Ragauskas, A. J. (2004). "Review of current and future softwood kraft lignin process chemistry," Indust. Crops Prod. 20(2), 131-141. DOI:

10.1016/j.indcrop.2004.04.016

Chaléat, C. M., Halley, P. J., and Truss, R. W. (2012). "Study on the phase separation of plasticized starch/poly(vinyl alcohol) blends," Polym. Degrad. Stabil. 97(10), 19301939. DOI: 10.1016/j.polymdegradstab.2012.03.001

Chen, G., Zhu, P. H., Kuang, Y. D., Liu, Y., Lin, D. H., Peng, C. X., Wen, Z. C., and Fang, Z. Q. (2017). "Durable superhydrophobic paper enabled by surface sizing of starch-based composite films," Appl. Surf. Sci. 409, 45-51. DOI: 10.1016/j.apsusc.2017.02.201

Chen, Y. Z., Zheng, J. A., Li, H., Zhang, Z. J. (2015). "The synthesis of styrene acrylate emulsion and its application in xerographic paper," J. Polym. Eng. 35(3), 199-207. DOI: $10.1515 /$ polyeng-2014-0058

Childers, M., and Daggett, V. (2017). "Insights from molecular dynamics simulations for computational protein design,” Molec. Sys. Design Eng. 2(1), 9-33. DOI: 10.1039/c6me00083e

Cobb, R. M., and Lowe, D. V. (1934). "A sizing test and a sizing theory," Tech. Assoc. Papers 17, 213-216.

Conde-Petit, B., Escher, F., and Nuessli, J. (2006). "Structural features of starch-flavor complexation in food model systems," Trends Food Sci. Technol. 17(5), 227-235. DOI: $10.1016 /$ j.tifs.2005.11.007

Cui, Y. J., and Jing, Y, (2012). "Synthesis and application of cationic styrene acrylic ester polymer surface sizing agent," Proceeding of the $4^{\text {th }}$ International Conference on Pulping, Papermaking and Biotechnology (ICPPB '12), Y. Jin, Z. Wang, and W. Wu (eds.), Nanjing Forestry Univ., pp. 635-639.

Cunha, A. G., Fernandes, S. C. M., Friere, C. S. R., Silvestre, A. J. C., Neto, C. P., and Gandini, A. (2008). "What is the real value of chitosan's surface energy?"

Biomacromol. 9, 610-614. DOI: 10.1021/bm701199g

Cushing, M. L. (1979). "Surface sizing," in: Pulp and Paper Chemistry and Chemical Technology, $3^{\text {rd }}$ Ed., J. P. Casey (ed.), Wiley-Interscience, New York, Vol. 3, pp. 1667-1714.

Dahmen, K., Mertens, R., Muller, T., and Schulte, J. (1999). "Paper-sizing agents containing aqueous, solvent-free dispersions of cationic polymers and method of preparing sized paper by using these agents," U.S. Patent No. 5,954,921, Evonik Stockhausen Gmbh.

Dannhauser, W., Glaze, W. H., Dueltgen, R. L., and Ninomiya, K. (1960). "Evidence from intrinsic viscosity and sedimentation for hypercoiled configurations of styrenemaleic acid copolymer," Journal of Physical Chemistry 64(7), 954-955. DOI: $10.1021 / \mathrm{j} 100836 \mathrm{a} 517$

David, D. J., and Sincock, T. F. (1992). "Estimation of miscibility of polymer blends using the solubility parameter concept," Polymer 33(21), 4505-4514. DOI: 10.1016/0032-3861(92)90406-M

Davison, R. W. (1975). “The sizing of paper," TAPPI 58(3), 48-57. 
dePierne, O. S., Dauplaise, D. L., and Proverb, R. J. (1992). "Styrene/acrylic type polymers for use as surface sizing agents," U.S. Patent No. 5,122,568.

Dimic-Misic, K., Gane, P. A. C., and Paltakari, J. (2013). "Micro- and nanofibrillated cellulose as a rheology modifier additive in CMC-containing pigment-coating formulations," Indust. Eng. Chem. Res. 52(45), 16066-16083. DOI: $10.1021 /$ ie 4028878

Domene-López, D., Guillén, M. M., Martin-Gullon, I., García-Quesada, J. C., and Montalbán, M. G. (2018). "Study of the behavior of biodegradable starch/polyvinylalcohol/rosin blends," Carbohydr. Polym. 202, 299-305. DOI: 10.1016/j.carbpol.2018.08.137.

Dong, L. Y., Hu, H. R., Cheng, F., and Yang, S. (2015). "The water resistance of corrugated paper improved by lipophilic extractives and lignin in APMP effluent," $J$. Wood Sci. 61(4), 412-419. DOI: 10.1007/s10086-015-1480-0

Dong, L. Y., Hu, H. R., Yang, S., and Cheng, F. (2014). “Grafted copolymerization modification of hemicellulose directly in the alkaline peroxide mechanical pulping (APMP) effluent and its surface sizing effects on corrugated paper," Indust. Eng. Chem. Res. 53(14), 6221-6229. DOI: 10.1021/ie4044423

Dudowicz, J., Freed, K. F., and Douglas, J. F. (2013). "Solvation of polymers as mutual association. I. General theory," J. Chem. Phys. 138(16), article no. 164901. DOI: $10.1063 / 1.4800074$

Dumas, D. H. (1981). “An overview of cellulose-reactive sizes," TAPPI 64(1), 43-46.

Ehrhardt, S., and Leckey, J. (2020). "Fluid resistance: The sizing of paper," in: Make Paper Products Stand Out, Strategic Use of Wet End Chemical Additives, M. A. Hubbe and S. Rosencrance (eds.), TAPPI Press, Atlanta, pp. 53-75.

Exner, R. (2002). "Synthesis and application of polymer sizing agents," Paper Technol. 43, 45-51.

Fanta, G. F., Felker, F. C., Hay, W. T., and Selling, G. W. (2017). "Increased water resistance of paper treated with amylose-fatty ammonium salt inclusion complexes," Indust. Crops Prod. 105, 231-237. DOI: 10.1016/j.indcrop.2017.04.060

Fechner, P. M., Wartewig, S., Kleinebudde, P., and Neubert, R. H. H. (2005). "Studies of the retrogradation process for various starch gels using Raman spectroscopy," Carbohydrate Research 340(16), 2563-2568. DOI: 10.1016/j.carres.2005.08.018

Fei, G. Q., Yan, T., Wang, H. H., Shen, Y. D., and Zou, J. (2017). "Micromorphology, phase behavior, and properties of environmental, multi-cross-linked polyurethane/ polyacrylate microemulsions based on in situ surfactant-free polymerization," Colloid Polym. Sci. 295(10), 1743-1755. DOI: 10.1007/s00396-017-4148-z

Fernandes, S. C. M., Freire, C. S. R., Silvestre, A. J. D., Desbrieres, J., Gandini, A., and Neto, C. P. (2010). "Production of coated papers with improved properties by using a water-soluble chitosan derivative," Indust. Eng. Chem. Res. 49(14), 6432-6438. DOI: 10.1021/ie100573z

Ferrer, A., Pal, L., and Hubbe, M. A. (2016). "Nanocellulose in packaging: Advances in barrier layer technologies," Industrial Crops and Products 95, 574-582. DOI: 10.1016/j.indcrop.2016.11.012

Ferry, J. D., Udy, D. C., Wu, F. C., Heckler, G. E., and Fordyce, D. B. (1951). "Titration and viscosity studies of 2 copolymers of maleic acid," J. Colloid Sci. 6(5), 429-442. DOI: $10.1016 / 0095-8522(51) 90014-1$ 
Fineman, I., and Hoc, M. (1978). "Surface properties, especially linting, of surface-sized fine papers - The influence of starch distribution and hydrophobicity," TAPPI J. 61(5), 433-446.

Finsy (1994). "Particle sizing by quasi-elastic light scattering," Advan. Colloid Interface Sci. 52, 79-143. DOI: 10.1016/0001-8686(94)80041-3

Flory, P. J. (1942). “Thermodynamics of high polymer solutions," J. Chem. Phys. 10, 5161. DOI: $10.1063 / 1.1723621$

Forsström, U., Fagerholm, K., and Saharinen, E. (2003). “The role of base paper porosity in MSP coating," Paperi ja Puu 85(8), 454-459.

Fredriksson, H., Silverio, J., Andersson, R., Eliasson, A. C., and Aman, P. (1998), "The influence of amylose and amylopectin characteristics on gelatinization and retrogradation properties of different starches," Carbohydr. Polym. 35(3-4), 119-134. DOI: $10.1016 / \mathrm{S} 0144-8617(97) 00247-6$

Gaiduchenya, G. M. (1973). "Effect of sizing with stearates on the hydrophobicity and mechanical strength of photographic base paper," Sb. Tr. Tsentr. Nauch.-Issled. Inst. Bumagi 1973(8), 78-83.

Garnier, G., Duskova-Smrckova, M., Vyhnalkova, R., Van de Ven, T. G. M., and Revol, J. F. (2000). "Association in solution and adsorption at an air-water interface of alternating copolymers of maleic anhydride and styrene," Langmuir 16(8), 37573763. DOI:10.1021/la991440a

Garrett, P. D., and Lee, K. I. (1998). "Characterization of polymers for paper surface sizings using contact angle methods," TAPPI J. 81(4), 198-203.

Gellerstedt, G. (2015). "Softwood kraft lignin: Raw material for the future," Indust. Crops Prod. 77, 845-854. DOI: 10.1016/j.indcrop.2015.09.040

Gharehkhani, S., Sadeghinezhad, E., Kazi, S. N., Yarmand, H., Badarudin, A., Safaei, M. R., and Zubir, M. N. M. (2015). "Basic effects of pulp refining on fiber properties - A review," Carbohydr. Polym. 115, 785-803. DOI: 10.1016/j.carbpol.2014.08.047

Gigac, J., Stankovská, M., Letko, M., and Opálená, E. (2014). "The effect of base paper properties on inkjet print quality," Wood Res. 59(5), 717-730.

Godbole, S., Gote, S., Latkar, M., and Chakrabarti, T. (2003). "Preparation and characterization of biodegradable poly-3-hydroxybutyrate-starch blend films," Bioresour. Technol. 86(1), 33-37. DOI: 10.1016/S0960-8524(02)00110-4

Guo, Y. H., Guo, J. J., Li, S. C., Li, X., Wang, G. S., and Huang, Z. (2013). “Properties and paper sizing application of waterborne polyurethane emulsions synthesized with TDI and IPDI," Colloids Surf. A - Physicochem. Eng. Aspects 427, 53-61. DOI: 10.1016/j.colsurfa.2013.03.017

Guo, Y. H., Guo, J. J., Miao, H., Teng, L. J., and Huang, Z. (2014). "Properties and paper sizing application of waterborne polyurethane emulsions synthesized with isophorone diisocyanate," Prog. Organic Coatings 77(5), 988-996. DOI:

10.1016/j.porgcoat.2014.02.003

Guo, Y. H., Li, S. C., Wang, G. S., Ma, W., and Zhen, H. (2012). "Waterborne polyurethane/poly(n-butyl acrylate-styrene) hybrid emulsions: Particle formation, film properties, and application," Prog. Organic Coatings 74(1), 248-256. DOI: 10.1016/j.porgcoat.2011.12.016

Hahn, D. E., and Hood, L. F. (1987). "Factors influencing corn starch-lipid complexing," Cereal Chem. 64(2), 81-85.

Hamerstrand, G. E., Heath, H. D., Phillips, B. S., Rankin, J. C., and Schulte, M. I. (1979). "Cationic surface sizes," Tappi 62(7), 35-38. 
Han, K. M., and Cho, B. U. (2016). "Effect of surface sizing of black liquor on properties of corrugated medium," BioResources 11(4), 10391-10403. DOI: 10.15376/biores.11.4.10391-10403

Hans, F., Karl, H., Gernot, W., Alfred, M., Georg, R. J., and Heinz, V. (1965). "Process of surface sizing paper with stable cationic-active plastic dispersions," U.S. Patent No. 3,74,874., BASF SE.

Hansen, C. (2007). Hansen Solubility Parameters: A User's Handbook, $2^{\text {nd }}$ Ed., CRC Press, Boca Raton, FL. DOI: 10.1201/9781420006834

Hiemstra, P. (1972). “Continuous chemical conversion,” Papeterie 94(9), 732, 735-738, 741.

Hiemstra, P., and Vanderme, J. (1969). "Coatings for offset printing made with different adhesives," TAPPI 52(2), 263.

Hoffreiter, B. T. (1980). "Natural products for wet-end addition," in: Pulp and Paper Chemistry and Chemical Technology, $3^{\text {rd }}$ Ed., J. P. Casey (ed.), Wiley, New York, NY, Ch. 14, pp. 1475-1514.

Horchani, H., Chaâbouni, M., Gargouri, Y., and Sayari, A. (2010). "Solvent-free lipasecatalyzed synthesis of long-chain starch esters using microwave heating:

Optimization by response surface methodology," Carbohydr. Polym. 79(2), 466-474. DOI: 10.1016/j.carbpol.2009.09.003

Hoyland, R. W., and Neill, M. P. (2001). "Factors affecting the frictional properties of paper - The effect of AKD neutral size," Paper Technol. 42(3), 45-373.

Hsieh, C. F., Liu, W. C., Whaley, J. K., and Shi, Y. C. (2019). "Structure, properties, and potential applications of waxy tapioca starches - A review," Trends Food Sci.

Technol. 83, 225-234. DOI: 10.1016/j.tifs.2018.11.022

Hubbe, M. A. (2007). "Paper's resistance to wetting - A review of internal sizing chemicals and their effects," BioResources 2(1), 106-145. DOI: 10.15376/biores.2.1.106-145

Hubbe, M. A. (2019). "Why, after all, are chitosan films hydrophobic?" BioResources 14(4), 7630-7631.

Hubbe, M. A., Chandra, R. P., Dogu, D., and van Velzen, S. T. J. (2019). "Analytical staining of cellulosic materials: A Review," BioResources 14(3), 7387-7464. DOI: 10.15376/biores.14.3.7387-7464

Hubbe, M. A., Lavoine, N., Lucia, L. A., and Dou, C. (2021). "Formulating bioplastic composites for biodegradability, recycling, and performance: A review," BioResources 16(1), 2021-2083.

Hubbe, M. A., and Pruszynski, P. (2020). "Greaseproof paper products: A review emphasizing ecofriendly approaches," BioResources 15(1), 1978-2004. DOI: 10.15376/biores.15.1.1978-2004

Hubbe, M. A., Sjöstrand, B., Nilsson, L., Kopponen, A., and McDonald, J. D. (2020). "Rate-limiting mechanisms of water removal during the formation, vacuum dewatering, and wet-pressing of paper webs: A review," BioResources 15(4), 96729755.

Hubbe, M. A., Tayeb, P., Joyce, M., Tyagi, P., Kehoe, M., Dimic-Misic, K., and Pal, L. (2017). "Rheology of nanocellulose-rich aqueous suspensions: A review," BioResources 12(4), 9556-9661. DOI: 10.15376/biores.12.1.2143-2233

Hughes, D. A., and Craig, W. L. (1950). "Enzyme conversion of starch for paper coating," Tappi 33(5), 253-256. 
Immel, S., and Lichtenthaler, F. W. (2000). "The hydrophobic topographies of amylose and its blue iodine complex," Starch - Stärke 52(1), 1-8. DOI: 10.1002/(SICI)1521379X(200001)52:1<1::AID-STAR1>3.0.CO;2-H

Inaoka, K., Nakata, T., and Hashiguchi, Y. (2009). "Cationic surface sizing agent and newsprint paper," U.S. Patent No. 2009/0068485 A1.

Inaoka, K., Nakata, T., and Hashiguchi, Y. (2011). "Cationic surface sizing agent and paper coated with the same," U.S. Patent No. 7,988,826 B2.

Iselau, F., Holmberg, K., and Bordes, R. (2017). "Surface treatment by hydrophobic particles: Influence of starch and ionic strength," ACS Sustain. Chem. Eng. 5(7), 6107-6115. DOI: 10.1021/acssuschemeng.7b00984

Iselau, F., Malmborg-Nyström, K., Holmberg, K., and Bordes, R. (2018). "Parameters influencing hydrophobization of paper by surface sizing," Nordic Pulp Paper Res. J. 33(1), 95-104. DOI: 10.1515/npprj-2018-3015

Iselau, F., Restorp, P., Andersson, M., and Bordes, R. (2015). "Role of the aggregation behavior of hydrophobic particles in paper surface hydrophobation," Colloids Surf. A - Physicochem. Eng. Aspects 483, 264-270. DOI: 10.1016/j.colsurfa.2015.04.013

Jansson, A., and Järnström, L. (2005). "Barrier and mechanical properties of modified starches," Cellulose 12(4), 423-433. DOI: 10.1007/s10570-004-6092-6

Jonhed, A., Andersson, C., and Järnström, L. (2008). "Effects of film forming and hydrophobic properties of starches on surface sized packaging paper," Packaging Technol. Sci. 21(3), 123-135. DOI: 10.1002/pts.783

Jonhed, A., and Järnström, L. (2009). "Influence of polymer charge, temperature, and surfactants on surface sizing of liner and greaseproof paper with hydrophobically modified starch," TAPPI J. 8(2), 33-38. DOI: 10.32964/TJ8.2.33

Karademir, A., and Hoyland, D. (2003). "The sizing mechanism of AKD and its effect on paper friction," Appita J. 56(5), 380-384.

Kasemwong, K., and Itthisoponkul, T. (2013). "Encapsulation of flavor compounds as helical inclusion complexes of starch," Advances in Applied Nanotechnology for Agriculture, B. Park and M. Appell (eds.), Ch. 14, ACS Symposium Series 1143, 235 245. DOI: $10.1021 / \mathrm{bk}-2013-1143 . c h 014$

Kjellgren, H., Gällstedt, M., Engström, G., and Järnström, L. (2006). "Barrier and surface properties of chitosan-coated greaseproof paper," Carbohyd. Polym. 65(4), 453-460.

DOI: $10.1016 /$ j.carbpol.2006.02.005

Klass, C. P. (1988). "Alternatives to the size press," PIMA 1998(9), 19-22.

Klass, C. P. (1990). "Trends and developments in size press technology," TAPPI Journal 73(12), 69-75.

Koningsveld, R. (1994). “Thermodynamics of polymer blends,” Macromol. Symp. 78, 113. DOI: $10.1002 /$ masy.19940780103

Kopacic, S., Ortner, A., Guebitz, G., Kraschitzer, T., Leitner, J., and Bauer, W. (2018). "Technical lignins and their utilization in the surface sizing of paperboard," Indust. Eng. Chem. Res. 57(18), 6284-6291. DOI: 10.1021/acs.iecr.8b00974

Koskela, J. P., Xiong, H. W., and Hormi, O. E. O. (2006). "Effect of water dispersible chemical derivatives on paper processing and performance," Nordic Pulp Paper Res. J. 21(5), 697-701. DOI: 10.3183/npprj-2006-21-05-p697-701

Kuge, T., and Takeo, K. (1968). "Complexes of starchy materials with organic compounds. Part II. Complex formation in aqueous solution and fractionation of starch by L-menthone," Agri. Biol. Chem. 32(10), 1232-1238. DOI: 10.1080/00021369.1968.10859210 
Kuleznev, V. N., Krokhina, L. S., Oganesov, Y. G., and Zlatsen, L. M. (1971). "Effect of molecular weight on mutual solubility of polymers," Colloid J. USSR 33(1), 81.

Latta, J. L. (1994). "Practical applications of styrene maleic anhydride surface treatment resins for fine paper sizing," TAPPI 1994 Papermakers Conference, pp. 399-406.

Lee, H. L., Shin, J. Y., Koh, C. H., Ryu, H., Lee, D. J., and Sohn, C. (2002). "Surface sizing with cationic starch: Its effect on paper quality and papermaking process," TAPPI J. 1(3), 34-40.

Lertsutthiwong, P., Nazhad, M. M., Chandrkrachang, S., and Stevens, W. F. (2004). "Chitosan as a surface sizing agent for offset printing paper," APPITA J. 57(4), 274280.

Lipponen, J., Grön, J., Bruun, S. E., and Laine, T. (2004). "Surface sizing with starch solutions at solids contents up to 18\%," J. Pulp Pap. Sci. 30(3), 82-90.

Lipponen, J., Pakarinen, J., Jääskeläinen, J., and Grön, J. (2005). "Mechanical properties of woodfree paper sheets at different surface size starch amounts," Paperi ja Puu/Paper and Timber 87(3), 170-175.

Liu, H. S., Yu, L., Chen, L., and Li, L. (2007). "Retrogradation of corn starch after thermal treatment at different temperatures," Carbohydr. Polym. 69(4), 756-762. DOI: 10.1016/j.carbpol.2007.02.011

Lourdin, D., Bizot, H., and Colonna, P. (1997). "Antiplasticization in starch-glycrerol films?” J. Appl. Polym. Sci. 63(8), 1047-1053. DOI: 10.1002/(SICI)10974628(19970222)63:8<1047::AID-APP11>3.0.CO;2-3

Lucas, R. (1918). "Ueber das Zeitgesetz des kapillaren Aufstiegs von Flüssigkeiten,” Kolloid Zeitschrift 23(1), 15-22. DOI: 10.1007/BF01461107

Mallory, G. (1923). "Why climb mount Everest? 'Because it's there' said Mallory," New York Times, March 18.

Maurer, H. W., and Kearney, R. L. (1998). "Opportunities and challenges of starch in the paper industry," Starch-Stärke 50(9), 396-402. DOI: 10.1002/(SICI)1521379X(199809)50:9<396::AID-STAR396>3.0.CO;2-8

Maurer, H. W. (2009). "Starch in the paper industry," Starch, $3^{\text {rd }}$ Ed., Elsevier, pp. 657713. DOI:10.1016/B978-0-12-746275-2.00018-5

Meng, S., Ma, Y., Sun, D. W., Wang, L. F., and Liu, T. Y. (2014). "Properties of starchpalmitic acid complexes prepared by high pressure homogenization," J. Cereal Sci. 59(1), 25-32. DOI: 10.1016/j.jcs.2013.10.012

Mešić, B., Järnström, L., Hjärthag, C., and Lestelius, M. (2004). "Effects of application temperature in paper surface sizing with temperature-responsive starch on water repellency and flexographic printability," APPITA J. 57(4), 281-298.

Miao, N. N., Zhang, M., Xu, X. L., Wang, L., and Qiu, J. H. (2016). "Verifying the interactions between PBS-based copolymers and starch composite materials by molecular dynamics," Acta Polym. Sinica 2016(4), 511-519.

Mikhaylova, Y., Adam, G., Haussler, L., Eichhorn, K. J., and Voit, B. (2006). "Temperature-dependent FTIR spectroscopic and thermoanalytic studies of hydrogen bonding of hydroxyl (phenolic group) terminated hyperbranched aromatic polyesters," J. Molec. Struc. 788, 80-88. DOI: 10.1016/j.molstruc.2005.11.020

Mikus, F. F., Hixon, R. M., and Rundle, R. E. (1946). "The complexes of fatty acids with amylose," J. Amer. Chem. Soc. 68(6), 1115-1123. DOI: 10.1021/ja01210a062

Miles, M. J., Morris, V. J., Orford, P. D., and Ring, S. G. (1985). "The roles of amylose and amylopectin in the gelation and retrogradation of starch," Carbohydr. Res. 135(2), 271-281. DOI: 10.1016/S0008-6215(00)90778-X 
Morrison, W. R., Law, R. V., and Snape, C. E. (1993). "Evidence for inclusion complexes of lipids with V-amylose in maize, rice and oat starches," J. Cereal Sci. 18(2), 107-109. DOI: 10.1006/jcrs.1993.1039

Mortazavi, M., and Nosonovsky, M. (2012). "A model for diffusion-driven hydrophobic recovery in plasma treated polymers," Appl. Surf. Sci. 258(18), 6876-6883. DOI: 10.1016/j.apsusc.2012.03.122

Moutinho, I. M. T., Ferreira, P. J. T., and Figueiredo, M. L. (2011). "Paper surface chemistry as a tool to improve inkjet printing quality," BioResources 6(4), 42594270.

Nguyen, N., Jordan, B., Aspler, J., and O’Neill, M. (1998). “Print and paper attributes that determine the quality of letterpress images on a commercial press," Proceedings of the International Printing and Graphic Arts Conference, Quebec, Canada, pp. 1-2.

Ni, Y. Y., and Jing, Y. (2019). "Research on improving the surface hydrophobicity of paper coated by poly-vinyl alcohol-itaconic acid grafting copolymer," Prog. Organic Coatings 131, 152-158. DOI: 10.1016/j.porgcoat.2019.02.006

Obiro, W. C., Sinha Ray, S., and Emmambux, M. N. (2012). "V-amylose structural characteristics, methods of preparation, significance, and potential applications," Food Rev. Int. 28, 412-438. DOI: 10.1080/87559129.2012.660718

Oja, M. E., Frederick, C. H., Van Nuffel, J., and Lambrechts, P. (1991). "Size presses: Starch runnability and paper properties," TAPPI Papermakers Conf. (Seattle), TAPPI Press, Atlanta, pp. 213-221.

Ono, H., and Deng, Y. (1997). “Cationic polystyrene-based paper sizing agents," Proc. TAPPI 1997 Engineering and Papermakers Conf., TAPPI Press, Atlanta, 837-849.

Ortega-Toro, R., Jimenez, A., Talens, P., and Chiralt, A. (2014). "Effect of the incorporation of surfactants on the physical properties of corn starch films," Food Hydrocolloids 38, 66-75. DOI: 10.1016/j.foodhyd.2013.11.011

Özdemir, M., Alp, M. Ö., Aytaç, A., and Deniz, V. (2017a). “A study of the properties of paper sized with styrene-butyl acrylate copolymers," Acta Physica Polonica A 132(3), 1098-1101. DOI: 10.12693/APhysPolA.132.1098

Özdemir, M., Aytaç, A., and Deniz, V. (2017b). "Investigation into the surface properties of papers sized with styrene-acrylate-cationic monomer based terpolymers," ACTA Phys. Polonica A 131(1), 178-181. DOI: 10.12693/APhysPolA.131.178

Pask, M. D. (1982). "Polyurethan(e)s for surface sizing," TAPPI Papermakers Conf. (Atlanta), pp. 57-61.

Peterlein, K., Schulde, F., Diedrich, K. M., and Kulisch, V. W. (1980). “Anionic paper surface sizing agent," U.S. Patent No. 4,200,559.

Polaczek, E., Starzyk, F., Malenki, K., and Tomasik, P. (2000). "Inclusion complexes of starches with hydrocarbons," Carbohydr. Polym. 43(3), 291-297. DOI: 10.1016/S0144-8617(00)00153-3

Prinz, M., and Schultz, W. S. (2006). "Sizing agents for wet end and surface application," Wochenblatt für Papierfabrikation 134(22), 1329-1335.

Proverb, R. (1999). "Achieving optimum print quality through sizing in impact \& nonimpact printing processes," Scientific \& Technical Advances in the Internal \& Surface Sizing of Paper \& Board. Florence, Italy: Pira International, pp. 1-12.

Putseys, J. A., Lamberts, L., and Delcour, J. A. (2010). “Amylose-inclusion complexes: Formation, identity and physico-chemical properties," J. Cereal Sci. 51(3), 238-247. DOI: $10.1016 /$ j.jcs.2010.01.011 
Radovanović, I., Jeremić, K., and Jovanović, S. (2007). "Synthesis of copolymer of styrene and ethylhexylmethacrylate for the application as sizing agent during paper production," Hemijska Industrija 61(4), 186-189. DOI: 10.2298/HEMIND0704186R

Rahmat, A. R., Rahman, W. A. W. A., Sin, L. T., and Yussuf, A. A. (2009). "Approaches to improve compatibility of starch filled polymer system: A review," Mater. Sci. Eng. C-Mater. Biol. Appl. 29(8), 2370-2377. DOI: 10.1016/j.msec.2009.06.009

Rankin, J. C., Phillips, B. S., Doane, W. M., and Russell, C. R. (1976). “Steam-jet cooking of unmodified and modified cereal flours. Evaluation of paste properties, papermaking uses, and flocculation activity," Stärke 28(5), 174-179. DOI: 10.1002/star.19760280508

Ratnayake, W. S., and Jackson, D. S. (2009). "Starch gelatinization," Advances in Food and Nutrition Research, Vol. 55, S. L. Taylor (ed.), pp. 221-268. DOI: 10.1016/S1043-4526(08)00405-1

Reinke, S. K., Hauf, K., Vieira, J., Heinrich, S., and Palzer, S. (2015). "Changes in contact angle providing evidence for surface alteration in multi-component solid foods," J. Phys. D - Appl. Phys. 48(6), article no. 464001. DOI: 10.1088/00223727/48/46/464001

Reisch, A., and Klymchenko, A. S. (2016). "Fluorescent polymer nanoparticles based on dyes: Seeking brighter tools for bioimaging," Small 12(15), 1968-1992. DOI: 10.1002/smll.201503396

Rennes, J. M. (1998). "Metering size press drying and web-handling systems," TAPPI J. 81(5), 73-77; 81(7), 62-64.

Roberts, J. C., Au, C. O., Clay, G. A., and Lough, C. (1987). "A study of the effect of cationic starch on dry strength and formation using C14 labelling," J. Pulp Paper Sci 13(1), J1-J5.

Roy, M. N., Roy, M. C., and Roy, K. (2015). "Investigation of an inclusion complex formed by ionic liquid and $\beta$-cyclodextrin through hydrophilic and hydrophobic interactions," RSC Advan. 5, 56717-56723. DOI: 10.1039/C5RA09823H

Rutschmann, M. A., Heiniger, J., Pliska, V., and Solms, J. (1989). "Formation of inclusion complexes of starch with different organic compounds. I. Method of evaluation of finding proviles with menthone as an example," LebensmittleWissenschaft und-Technologie 23(5), 70-79.

Sackmann, G., Beck, U., and Baumgen, H. (1986). "Surface sizing agents for paper," U.S. Patent No. 4,614,759, Bayer AG.

Sackmann, G., Kolb, G., Probst, J., Muller, F., and Baumgen, H. (1984). "Low-foam surface sizing agents for paper which contain copolymeric maleic anhydride semiamides," U.S. Patent No. 4,481,319.

Salas, C., Hubbe, M., and Rojas, O. J. (2019). "Nanocellulose applications in papermaking," in: Production of Materials from Sustainable Biomass Resources, Z. Fang, R. L. Smith, Jr., and X.-F. Tian (eds.), Biofuels and Biorefineries Ser. 9, Springer, New York, Chapter 3, pp. 61-96. DOI: 10.1007/978-981-13-3768-0_3

Sarka, E., and Dvoracek, V. (2017). "Waxy starch as a perspective raw material (a review)," Food Hydrocolloids 69, 402-409. DOI: 10.1016/j.foodhyd.2017.03.001

Schirmer, M., Hochstotter, A., Jekle, M., Arendt, E., and Becker, T. (2013). "Physicochemical and morphological characterization of different starches with variable amylose/amylopectin ratio," Food Hydrocol. 32(1), 52-63. DOI: 10.1016/j.foodhyd.2012.11.032 
Schurmann, H., Weissen, H.-J., and Schloter, K. (1989). "Paper sizing agents, the manufacture and use of same," U.S. Patent No. 4,839,415.

Schweizer, K. S., and Singh, C. (1995). "Microscopic solubility-parameter theory of polymer blends - General predictions," Macromol. 28(6), 2063-2080. DOI:

10.1021/ma00110a046

Seo, M. S., Youn, H. J., and Lee, H. L. (2020). "Penetration control of surface sizing starch using cationic PAM and its effect on the bending stiffness of paper," BioResources 15(3), 5489-5502.

Shen, Y. D., Wang, L., Yang, X. W., and Li, G. H. (2010). "Study on the preparation of cationic surface sizing agent of polyurethane/polyacrylate composite emulsion with core-shell structure," Chung-kuo Tsao Chih/China Pulp and Paper

Shibihara, Y., and Tominaga, Y. (1975). "Surface sizing composition," U.S. Patent No. $3,925,328$.

Shreier, M. J. (1997). “One size doesn't fit all,” PaperAge, 1.

Shirazi, M., Esmail, N., Garnier, G., and van de Ven, T. G. M. (2008). "Starch penetration into paper in a size press," J. Dispersion Sci. Technol. 25(4), 457-468. DOI: $10.1081 /$ DIS-200025714

Shrimali, K., Atluri, V., Wang, X. M., and Miller, J. D. (2018). "Adsorption of corn starch molecules at hydrophobic mineral surfaces," Colloids Surf. A-Physicochem. Eng. Aspects 546, 194-202. DOI: 10.1016/j.colsurfa.2018.03.001

Singh, K. M., Anderson, D. W., Froass, P. M., Hong, Y., Hohan, K. K., Arnson, T. A., and Huang, Y. C. (2010). "Paper substrates containing high surface sizing and low internal sizing and having high dimensional stability," U.S. Patent No. 7,736,466 B2.

Slonimskii, G. L. (1958). "Mutual solubility of polymers and properties of their mixtures,” J. Polym. Sci. 30(212), 625-637. DOI: 10.1002/pol.1958.1203012153

Sodeyama, T., Hayashi, Y., and Inaoka, K. (2014). "Method for producing cationic surface sizing agent, and sizing agent obtained by method," U.S. Patent No. 2014/0023872, Harima Chem. Inc.

Sodeyama, T., Hayashi, Y., and Inaoka, K. (2016). "Method for producing cationic surface sizing agent, and sizing agent obtained by method," U.S. Patent No. 9,303,361, Harima Chem. Inc.

Song, F., Zhang, L. M., Li, N. N., and Shi, J. F. (2009). "In situ crosslinkable hydrogel formed from a polysaccharide-based hydrogelator," Biomacromol. 10(4), 959-965. DOI: $10.1021 / \mathrm{bm} 801500 \mathrm{w}$

Stanescu, V. N., Olteanu, M., Florea-Spiroiu, M., Pincu, E., and Meltzer, V. (2011). "Starch/chitosan film forming hydrogel," Revue Roumaine de Chimie 56(8), 827-832.

Stankovska, M., Gigac, J., Letko, M., and Opalena, E. (2014). "The effect of surface sizing on paper wettability and on properties of inkjet prints," Wood Res. 59(1), 6776.

Strazdins, E. (1989). “Critical phenomena in rosin sizing," TAPPI J. 67(4), 110-113.

Swanson, J. W., and Cordingly, S. (1959). "Surface chemical studies on pitch. 2. The mechanism of the loss of absorbency and development of self-sizing in papers made from wood pulps," TAPPI 42(10), 812-819.

Takaki, T., Ooyanagi, S., Tanabe, M., and Itoh, H. (1997). "Sizing mechanism of hydrophobically modified polyacrylamides," Kami Pa Gikyoshi 51(2), 286-291.

Tester, R. F., Karkalas, J., and Qi, X. (2004). "Starch - Composition, fine structure and architecture,” J. Cereal Sci. 39(2), 151-165. DOI: 10.1016/j.jcs.2003.12.001 
Thirathumthavorn, D., and Charoenrein, S. (2006). "Thermal and pasting properties of native and acid-treated starches derivatized by 1-octenyl succinic anhydride," Carbohydr. Polym. 66(2), 258-265. DOI: 10.1016/j.carbpol.2006.03.016

Tolstoguzov, V. (1999). “Origins of globular structure in proteins. Hypothesis," FEBS Lett. 444, 145-148. DOI: 10.1016/S0014-5793(99)00040-X

Tolstoguzov, V. (2003). "Thermodynamic considerations of starch functionality in foods," Carbohydr. Polym. 51(1), 99-111. DOI: 10.1016/S0144-8617(02)00171-6

Tolstoguzov, V. (2004). "Why were polysaccharides necessary?," Origins Life Evol. Biospheres 34(6), 571-597. DOI: 10.1023/B:ORIG.0000043127.18942.c4

Tominaga, Y., and Shibahara, Y. (1978). "Surface sizing compositions for paper," U.S. Patent No. 4,115,331. Sanyo Chem. Ind. Ltd.

Tompkins, T. W., Sharma, A. H., and Shepler, J. (1990). "Use of synthetic surface sizes on an alkaline base stock," TAPPI Neutral/Alkaline Pmkg. Short Course (Orlando) notes, pp. 79-89.

Triantafillopoulos, N. G. (1996). Paper Coating Viscoeslasticity and its Significance in Blade Coating, TAPPI Press, Atlanta.

Ullmann, B. (1987). "Rosin size as surface sizing - A particularly economical process," Zellstoff und Papier 36(4), 137-140.

vanSoest, J. J. G., Benes, K., deWit, D., and Vliegenthart, J. F. G. (1996a). "The influence of starch molecular mass on the properties of extruded thermoplastic starch," Polymer 37(16), 3543-3552. DOI: 10.1016/0032-3861(96)00165-6

Varnell, D. F. (2000). "Process for surface sizing paper and paper prepared thereby," U.S. Patent No. 6,051,107, Solenis Technol. LP.

Veis, A. (2011). "A review of the early development of the thermodynamics of the complex coacervation phase separation," Advan. Colloid Interface Sci. 167, 2-11. DOI: $10.1016 /$ j.cis.2011.01.007

Velho, J., and Gomes, C. (1995). "Effect of kaolin grades of different quality on paper properties," Investig. Tecnica Papel 125, 585-599.

Vrentas, J. S., and Duda, J. L. (1977). "Diffusion in polymer-solvent systems .2. predictive theory for dependence of diffusion-coefficients on temperature, concentration, and molecular-weight," J. Polym. Sci. Pt. B-Polym. Phys. 15(3), $417-$ 439. DOI: 10.1002/pol.1977.180150303

Wang, H. H., Fan, J., Fei, G. Q., Lan, J., and Zhao, Z. X. (2015a). "Preparation and property of waterborne UV-curable chain-extended polyurethane surface sizing agent: Strengthening and waterproofing mechanism for cellulose fiber paper," J. Appl. Polym. Sci. 132(31), article no. 42354. DOI: 10.1002/app.42354

Wang, S., Zhang, F., Chen, F., and Pang, Z. (2013) "Preparation of a crosslinking cassava starch adhesive and its application in coating paper," BioResources 8(3), 3574-3589. DOI:10.15376/biores.8.3.3574-3589

Wang, S. J., Li, C. L., Copeland, L., Niu, Q., and Wang, S. (2015b). "Starch retrogradation: A comprehensive review," Comprehensive Reviews in Food Science and Food Safety 14(5), 568-585. DOI: 10.1111/1541-4337.12143

Wang, T., Simonsen, J., and Biermann, C. J. (1997). "A new sizing agent: Styrenemaleic anhydride copolymer with alum or iron mordants," Tappi J. 80(1), 277-282.

Wang, X. C., Chen, K., Li, W., Hao, D. Y., and Guo, P. Y. (2019). “A paper sizing agent based on leather collagen hydrolysates modified by glycol diglycidyl ether and its compound performance," Int. J. Biol. Macromol. 124, 1205-1212. DOI: 10.1016/j.ijbiomac.2018.12.047 
Wang, X. C., Chen, K., Li, W., and Xue, K. K. (2018). "Synthesis and properties of collagen surface-sizing agent modified by epoxy compound," BioResources 13(4), 8329-8341. DOI: 10.15376/biores.13.4.8329-8341

Wang, X. C., Hao, X. L., and Qiang, T. T. (2013). "Preparation and sizing performance of the modified collagen surface sizing agent," in: Frontiers of Manufacturing and Design Science III, W. P. Sung and R. Chen (eds.), Applied Mechanics and Materials series, Vol. 271-272, pp. 367-371. DOI: 10.4028/www.scientific.net/AMM.271272.367

Wang, Y., and Fang, S. J. (2015). "Preparation and characterization of cationic siliconeacrylic latex surface sizing agent," Prog. Organic Coatings 88, 144-149. DOI: 10.1016/j.porgcoat.2015.06.031

Washburn, E. W. (1921). "The dynamics of capillary flow," Physics Review 17(3), 273 283. DOI: 10.1103/PhysRev.17.273

Wasser, R. B. (1987). "The reactivity of alkenyl succinic anhydride: Its pertinence with respect to alkaline sizing," J. Pulp Paper Sci. 13(1), J29-J32.

Wulff, G., Steinert, A., and Höller, O. (1998). "Modification of amylose and investigation of its inclusion behavior," Carbohydr. Res. 307, 19-31. DOI: 10.1016/S0008-6215(97)10097-0

$\mathrm{Xu}$, J. F., and Hu, H. R. (2012). "Preparation and characterization of styrene acrylate emulsion surface sizing agent modified with rosin," J. Appl. Polym. Sci. 123(1), 611616. DOI: 10.1002/app.34495

Xue, M. M., Cheng, L. S., Faustino, I., Guo, W. L., and Marrink, S. J. (2018). "Molecular mechanism of lipid nanodisk formation by styrene-maleic acid copolymers," Biophys. J. 115(3), 494-502. DOI: 10.1016/j.bpj.2018.06.018

Yamamoto, T., Orimi, N., Urakami, N., and Sawada, K. (2005). "Molecular dynamics modeling of polymer crystallization; from simple polymers to helical ones," Faraday Discuss. 128, 75-86. DOI: 10.1039/b406069e

Yan, X. H., Ji, Y. X., and He, T. (2013). "Synthesis of fiber crosslinking cationic latex and its effect on surface properties of paper," Prog. Organic Coatings 76(1), 11-16. DOI: 10.1016/j.porgcoat.2012.08.003

Yang, J. L., Gao, C. M., Lv, S. Y., Chen, M. J., and Liu, M. Z. (2015). "Polymeric micelles based on starch as drug carriers," Acta Polym. Sinica 2015(6), 617-623.

Yang, N., and Deng, Y. L. (2000). "Paper sizing agents from micelle-like aggregates of polystyrene-based cationic copolymers," J. Appl. Polymer Sci. 77(9), 2067-2073. DOI: 10.1002/1097-4628(20000829)77:9<2067::AID-APP24>3.0.CO;2-2

Yasuda, H., Okuno, T., Sawa, Y., and Yasuda, T. (1995). "Surface configuration change observed for Teflon-PFA on immersion in water," Langmuir 11(8), 3255-3260. DOI: 10.1021/la00008a060

Zhang, L. M. (2001). "Cellulosic associative thickeners," Carbohydr. Polym. 45(1), 1-10. DOI: $10.1016 / \mathrm{S} 0144-8617(00) 00276-9$

Zhou, J., Ren, L. L., Tong, J., and Ma, Y. H. (2009). "Effect of surface esterification with octenyl succinic anhydride on hydrophilicity of corn starch films," J. Appl. Polym. Sci. 114(2), 940-947. DOI: 10.1002/app.30709

Zhu, F. (2015). "Interactions between starch and phenolic compound," Trends Food Sci. Technol. 43(2), 129-143. DOI: 10.1016/j.tifs.2015.02.003 
Zhu, K., Li, X. R., Wang, H. H., Fei, G. Q., and Li, J. Y. (2016). "Properties and paper sizing application of waterborne polyurethane microemulsions: Effects of extender, cross-linker, and polyol," J. Appl. Polym. Sci. 133(25), article no. 43211. DOI:

10.1002/app.43211 